[This document contains the author's accepted manuscript. For the publisher's version, see the link in the header of this document.]

\title{
The Belief-Function Approach to Aggregating Audit Evidence
}

\author{
By Rajendra P. Srivastava \\ The University of Kansas
}

\section{Paper citation:}

Srivastava, Rajendra. (1995) The Belief-Function Approach to Aggregating Audit Evidence.

International Journal of Intelligent Systems, 10 (3), 329-356.

\begin{abstract}
:
In this article, we present the belief-function approach to aggregating audit evidence. The approach uses an evidential network to represent the structure of audit evidence. In turn, it allows us to treat all types of dependencies and relationships among accounts and items of evidence, and thus the approach should help the auditor conduct an efficient and effective audit. Aggregation of evidence is equivalent to propagation of beliefs in an evidential network. The paper describes in detail the three major steps involved in the propagation process. The first step deals with drawing the evidential network representing the connections among variables and items of evidence, based on the experience and judgment of the auditor. We then use the evidential network to determine the clusters of variables over which we have belief functions. The second step deals with constructing a Markov tree from the clusters of variables determined in step one. The third step deals with the propagation of belief functions in the Markov tree. We use a moderately complex example to illustrate the details of the aggregation process.
\end{abstract}


International Journal of Intelligent Systems, Vol. 10, No. 3, March 1995, pp. 329-356

\title{
The Belief-Function Approach to Aggregating Audit Evidence\#
}

\author{
Rajendra P. Srivastava* \\ Professor, and Deloitte \& Touche Faculty Fellow \\ School of Business, University of Kansas \\ Lawrence, Kansas 66045
}

June 29, 1993

\# This research has been partially supported by Deloitte \& Touche through their Deloitte \& Touche Faculty Fellowship at the School of Business, The University of Kansas.

* The author would like to thank Peter Gillett, Glenn Shafer, and Prakash Shenoy for their insightful comments on an earlier version of the paper. 


\title{
The Belief-Function Approach to Aggregating Audit Evidence
}

\author{
ABSTRACT \\ In this article, we present the belief-function approach to aggregating audit evidence. The \\ approach uses an evidential network to represent the structure of audit evidence. In turn, it \\ allows us to treat all types of dependencies and relationships among accounts and items of \\ evidence, and thus the approach should help the auditor conduct an efficient and effective audit. \\ Aggregation of evidence is equivalent to propagation of beliefs in an evidential network. The \\ paper describes in detail the three major steps involved in the propagation process. The first step \\ deals with drawing the evidential network representing the connections among variables and \\ items of evidence, based on the experience and judgment of the auditor. We then use the \\ evidential network to determine the clusters of variables over which we have belief functions. \\ The second step deals with constructing a Markov tree from the clusters of variables determined \\ in step one. The third step deals with the propagation of belief functions in the Markov tree. We \\ use a moderately complex example to illustrate the details of the aggregation process.
}




\section{The Belief-Function Approach to Aggregating Audit Evidence}

\section{INTRODUCTION}

In recent years, there has been a considerable interest in the application of belief functions to auditing. Akresh, Loebbecke and Scott (1988) have mentioned that belief functions provide a flexible and adaptable way to combine evidence from a variety of sources. Shafer and Srivastava (1990) contend that uncertainty in the audit evidence cannot be fully described in terms of probability; the belief-function theory provides a better framework. Recently, Srivastava and Shafer (1992) have discussed the problems with interpreting audit risk as probabilities and have provided a belief-function interpretation of the risk that makes intuitive sense. They have also derived belief-function formulas for audit risk. However, they derive these formulas under the assumptions that (1) the evidential structure is a tree ${ }^{1},(2)$ all the items of evidence are affirmative $^{2},(3)$ the relationships among accounts and audit objectives are all 'and' relationships $^{3}$, and (4) all the variables in the tree are binary. (The variables in the tree represent various audit objectives, accounts, and the financial statements as a whole.)

It is important to point out that, in the 'real world,' auditors deal with situations where the above assumptions are not necessarily valid. The question is how do we aggregate various items of evidence in auditing to make decisions under such conditions? The answer lies partly in the work of Shenoy and Shafer (1986) on propagating beliefs in a Markov tree (see, also, Shafer, Shenoy and Mellouli 1987; Shenoy and Shafer 1990) and partly in the work of Kong (1986) on constructing a Markov tree from a 'hypergraph.' However, we are faced with several other questions: (1) What is a Markov tree? (2) What is a hypergraph? (3) How do we construct a hypergraph from an evidential network? (4) How do you construct a Markov tree from a hypergraph? The purpose of this paper is to provide answers to these questions and demonstrate how to combine audit evidence in a network in the belief-function formalism.

Aggregation of evidence in a network, in fact, is equivalent to propagation of beliefs in the network. In this paper, we will simplify the propagation process by directly constructing a 
Markov tree from the evidential network, without talking about hypergraphs. In general, the propagation scheme involves three major steps. The first step is to draw the evidential network representing the connections among variables and items of evidence, based on the experience and judgment of the auditor. We then use the evidential network to determine the clusters of variables over which we have belief functions. The second step is to construct a Markov tree from the clusters of variables determined in step one. The basic concepts related to a Markov tree, and the process for constructing such a tree from an evidential network, are discussed in Appendix A. The third step deals with the propagation of belief functions in the Markov tree developed in step two. The aggregation of evidence in an actual audit would become very complex without the aid of a computer. Shafer, Shenoy and Srivastava (1988) have developed such a program that automates the aggregation process (also, see Srivastava, Shenoy and Shafer 1990). Recently, Srivastava (1993), and Srivastava and Johns (1992) have demonstrated the use of the software in audit planning and evaluation. However, neither of these papers demonstrate the mechanism of combining audit evidence in an evidential network which is the main purpose of this paper.

In this article, we plan to demonstrate, in detail, the steps involved in the aggregation process starting from constructing the evidential network appropriate in a given audit to propagating strengths of various items of evidence, i.e., beliefs, in the network, using a moderately complex example. We want to point out that the process described here is valid in all situations whether the variables are binary or not, the items of evidence are affirmative or not, and the relationships among accounts or audit objectives are 'and' or not. However, for simplicity of exposition and for numerical tractability, we have considered in our numerical example only binary variables, affirmative items of evidence, and 'and' relationships. Since we have limited space in the paper, we will not discuss the other cases.

We should also point out that the approach discussed here allows us to combine items of evidence at all levels of the account (the audit objective level, the class of transactions' level, the account level, and the financial statement level). Furthermore, it allows us to treat 
interrelationships among accounts, among audit objects, and among items of evidence. In turn, we believe that the approach should help the auditor conduct an efficient and effective audit.

The efficiency in the audit process will be achieved because the assurance from the positive items of evidence in the network would be combined at its full strength. For example, suppose the auditor determines that the confirmation procedure of accounts receivable provides 0.9 degree of support to both 'Valuation' and 'Existence' objectives of the account. It may appear that the auditor is performing only one procedure for confirmations, but, in fact, he or she is processing two separate pieces of information: one for 'Valuation' and the other for 'Existence.' If we assume that the two pieces are independent, as done in the traditional approach (see, i.e., Leslie, Aldersley, Cockburn, and Reiter 1986), the combined degree of support that the account is fairly stated (i.e., the two objectives are met simultaneously, assuming only two audit objectives of the account $)$ is $0.81(=0.9 \times 0.9)$. However, since the two pieces of information are coming from the same source, the confirmation, the assumption that they are independent is not valid. When we treat the two pieces as interdependent, the total degree of support for both the objectives becomes 0.9 . Thus, ignoring interdependencies among the items of evidence will lead to under utilization of the strength of evidence and hence inefficiency in the audit process.

Similarly, the effectiveness will be achieved due to the reason that the negative items of evidence would be considered at its full strength and would force the auditor to perform more of the same procedure or perform certain other procedures to achieve the desired overall belief that the account is fairly stated. If the auditor is not able to achieve the desired level of overall belief that the account is fairly stated then he or she will either propose an adjusting entry to the account or refuse to give an unqualified opinion on the account.

The remainder of the paper is divided into six sections. In Section II, we discuss how to construct an evidential network for an audit and identify clusters of variables over which we have belief functions. In Section III, we illustrate the approach of constructing a Markov tree for an evidential network. In Section IV, we discuss the results. In Section V, we provide a summary and conclusion of our study, consider the limitations of the study, and discuss the problems for 
future research. Finally, in Appendix A, we briefly discuss the concepts related to a Markov tree and describe Kong's (1987) algorithm for constructing a Markov tree from a set of clusters of variables over which we have belief functions.

\section{EVIDENTIAL NETWORK AND CLUSTER OF VARIABLES}

We want to construct an evidential network in an audit to identify the relationship among the variables, and between the variables and the items of evidence. The variables in the network represent various audit objectives, accounts, and the financial statements. As discussed by Dutta and Srivastava (1992), such a network allows one to treat all types of dependencies such as dependency between the items of evidence, dependency between accounts, and dependency between errors.

Figure 1 represents an evidential network for the audit of accounts receivable. For simplicity, we assume that the accounts receivable account (AR) has only two relevant audit objectives: Existence (E) and Valuation (V). This means that the accounts receivable balance is not materially misstated if existence and valuation objectives of the account have been met. Next, we relate these objectives with the transaction stream objectives. We know that the accounts receivable existence objective is met ${ }^{4}$ when sales have occurred (SO) and cash receipts are complete (CC) (Leslie, Aldersley, Cockburn, and Reiter 1986). Similarly, valuation objective of accounts receivable is met when cash receipts are properly valued $(\mathrm{CV})$ and sales are properly valued (SV). Thus, in our example, we are interested in the following set of variables: $X=\{A R$, $\mathrm{E}, \mathrm{V}, \mathrm{CC}, \mathrm{CV}, \mathrm{SO}, \mathrm{SV}\}$.

\section{Figure 1 here}

As the first step in drawing the evidential network, we represent the seven variables, AR, E, $\mathrm{V}, \mathrm{CC}, \mathrm{CV}, \mathrm{SO}$, and SV, as ellipses in Figure 1. Next, we connect the variables to each other through appropriate relational nodes. As discussed in the previous paragraph, we know that AR is not materially misstated when variables $\mathrm{E}$ and $\mathrm{V}$ have been met. We will express such a relationship through an 'and' node. An 'and' node in a network implies that the variable on its left 
is met if and only if the variables on its right are met. We use 'and' nodes to relate CC and SO to E, and CV and SV to V in Figure 1. However, we can connect the variables through some other relationships such as 'or,' 'nor,' or 'exclusive or,' especially in the case of three variables, if we consider these relationships to be appropriate. These are categorical relationships. However, one can develop relationships among the variables that may involve uncertainties. Such relationships are more common in the medical field. For example, certain symptoms may relate to a given disease or a set of diseases with a given level of uncertainty and to another set of diseases with another level of uncertainty. The nature of the relationship determines the frame of the relational node and the $\mathbf{m}$-values for the node (see Section IV and also the second note in Table 2). In auditing, however, the use of 'and' relationship is quite common (see, e.g., Leslie, et. al 1986).

Next, we connect all the items of evidence to the nodes on which they directly bear. We represent an item of evidence by a rectangular box. An item of evidence may consist of one or more than one audit procedures. We use the audit procedures described by Arens and Loebbecke (1991) to construct the network in Figure 1 (see Table 1 for details). However, we have somewhat simplified the mapping for computational simplicity. It is not critical here to argue whether we have mapped the network correctly; we are simply using the network as an example to illustrate the general approach.

Table 1 here 
The next step is to determine the clusters of variables over which we have belief functions. This step is easy once we have drawn the network. We simply identify the variable or the set of variables to which an item of evidence is connected. For example, we have five one-variable subsets of $\mathrm{X},\{\mathrm{AR}\},\{\mathrm{CC}\},\{\mathrm{CV}\},\{\mathrm{SO}\}$, and $\{\mathrm{SV}\}$, for which we have at least one item of evidence directly bearing on each variable, i.e., we have at least one belief function on each variable. Next, we know that Evidence 11 bears directly on variables $\mathrm{E}$ and V, and Evidence 7 directly bears on $\mathrm{CC}$ and $\mathrm{CV}$, therefore we have two two-variable clusters or subsets of $\mathrm{X}:\{\mathrm{E}, \mathrm{V}\}$, and $\{\mathrm{CC}, \mathrm{CV}\}$, over which we have belief functions.

For the variables that are related through a relational node, we simply put them in one cluster and use the definition of the relationship to determine the belief function for the cluster. Based on the relationships discussed above, we have three clusters of variables: $\{\mathrm{AR}, \mathrm{E}, \mathrm{V}\}$, $\{\mathrm{E}, \mathrm{CC}, \mathrm{SO}\}$, and $\{\mathrm{V}, \mathrm{CV}, \mathrm{SV}\}$. The belief functions for these clusters are determined by the corresponding relationships. This completes the process of identifying clusters of variables over which we have belief functions. We will denote this set of clusters by $\mathrm{H}=\{\{\mathrm{AR}\},\{\mathrm{CC}\},\{\mathrm{CV}\}$, $\{\mathrm{SO}\},\{\mathrm{SV}\},\{\mathrm{E}, \mathrm{V}\},\{\mathrm{CC}, \mathrm{CV}\},\{\mathrm{AR}, \mathrm{E}, \mathrm{V}\},\{\mathrm{E}, \mathrm{CC}, \mathrm{SO}\},\{\mathrm{V}, \mathrm{CV}, \mathrm{SV}\}\}$ and use it to construct a Markov tree in the next section.

\section{CONSTRUCTION OF A MARKOV TREE}

Since the concepts of a Markov tree may not be familiar to readers of this article, we have discussed them in Appendix A and have provided Kong's one-step-look-ahead algorithm (Kong 1986) for constructing a Markov tree from an evidential network. In this section, we show step by step how to construct such a tree from the set of clusters of variables, $\mathrm{H}$, for which we have belief functions. As discussed in Section II, for the evidential network in Figure 1, we have $\mathrm{H}=$ $\{\{\mathrm{AR}\},\{\mathrm{CC}\},\{\mathrm{CV}\},\{\mathrm{SO}\},\{\mathrm{SV}\},\{\mathrm{E}, \mathrm{V}\},\{\mathrm{CC}, \mathrm{CV}\},\{\mathrm{AR}, \mathrm{E}, \mathrm{V}\},\{\mathrm{E}, \mathrm{CC}, \mathrm{SO}\},\{\mathrm{V}, \mathrm{CV}, \mathrm{SV}\}\}$.

We now use Kong's algorithm to construct a Markov tree (see Appendix A for details). 


\section{Iteration One, $\mathbf{i}=1$}

We have $\mathrm{U}_{0}=\{\mathrm{AR}, \mathrm{E}, \mathrm{V}, \mathrm{CC}, \mathrm{CV}, \mathrm{SO}, \mathrm{SV}\}, \mathrm{H}_{0}=\{\{\mathrm{AR}\},\{\mathrm{CC}\},\{\mathrm{CV}\},\{\mathrm{SO}\},\{\mathrm{SV}\}$, $\{\mathrm{E}, \mathrm{V}\},\{\mathrm{CC}, \mathrm{CV}\},\{\mathrm{AR}, \mathrm{E}, \mathrm{V}\},\{\mathrm{E}, \mathrm{CC}, \mathrm{SO}\},\{\mathrm{V}, \mathrm{CV}, \mathrm{SV}\}\}, \mathrm{N}=\varnothing$, and $\mathrm{E}=\varnothing$, where $\mathrm{N}$ stands for the set of nodes in the tree and $\mathrm{E}$ stands for the set of edges. In the beginning $\mathrm{N}$ and $\mathrm{E}$ are empty. We choose one variable at a time from $U_{0}$ and obtain the corresponding $G_{1}$ by determining the union of all the elements of $\mathrm{H}_{0}$ that contain the variable. We pick the variable to be $\mathrm{X}_{1}$ for which $\mathrm{G}_{1}$ has the least number of variables. In the case of a tie we choose ${ }^{5}$ the variable that comes first in the alphabetical order.

\section{Exhibit 1 here}

In the present case, we start with variable $A R$ as an element of $U_{0}$. We have only two elements $\{A R\}$, and $\{A R, E, V\}$ of $H_{0}$ that contain $A R$. We construct the union of these elements which yields $G_{1}=\{A R, E, V\}$ with three variables. Let us consider another element of $U_{0}$, say $E$. We form the union of the elements $\{\mathrm{E}, \mathrm{V}\},\{\mathrm{AR}, \mathrm{E}, \mathrm{V}\}$, and $\{\mathrm{E}, \mathrm{CC}, \mathrm{SO}\}$ of $\mathrm{H}_{0}$ that contain $\mathrm{E}$. This yields $\mathrm{G}_{1}=\{\mathrm{AR}, \mathrm{E}, \mathrm{V}, \mathrm{CC}, \mathrm{SO}\}$ with five variables. We repeat this process for all the elements in $\mathrm{U}_{0}$. All such $\mathrm{G}_{1}$ 's are given in column 2 in Exhibit 1 for $\mathrm{i}=1$. We notice that there is a three way tie between $\mathrm{AR}, \mathrm{SO}$, and $\mathrm{SV}$ for the least number of variables in $\mathrm{G}_{1}$. As mentioned earlier, we pick the variable AR because it comes first in the alphabetical order. Thus, $X_{1}=A R$, $\mathrm{G}_{1}=\{\mathrm{AR}, \mathrm{E}, \mathrm{V}\}$, and $\mathrm{F}_{1}=\mathrm{G}_{1}-\mathrm{X}_{1}=\{\mathrm{AR}, \mathrm{E}, \mathrm{V}\}-\{\mathrm{AR}\}=\{\mathrm{E}, \mathrm{V}\}$. These are listed in the first row of column 4 in Exhibit 1 for $i=1$.

The next step is to determine the set of nodes $\mathrm{N}$ and the set of edges $\mathrm{E}$. In the first iteration, $N$ contains $G_{1}$ and $F_{1}$ as nodes and any other element of $H_{0}$ that contains $X_{1}$ and not equal to $G_{1}$. In our case, we have only one element $\{A R\}$ in $H_{0}$ that contains $A R$, and thus $N$ contains three nodes $\mathrm{G}_{1}, \mathrm{~F}_{1}$, and $\{\mathrm{AR}\}$, i.e., $\mathrm{N}=\{\{\mathrm{AR}\},\{\mathrm{E}, \mathrm{V}\},\{\mathrm{AR}, \mathrm{E}, \mathrm{V}\}\}$. These nodes are drawn in Figure 2 as ellipses with a thin boundary.

Figure 2 here 
According to the algorithm, we form an edge between $G_{1}$ and $F_{1}$ and also between $G_{1}$ and any other element of $H_{0}$ that contains $X_{1}$ and is not equal to $G_{1}$. Graphically it means that we connect $F_{1}$ to $G_{1}$ and all other elements of $H_{0}$ containing $X_{1}$ (that is not equal to $G_{1}$ ) to $G_{1}$. In our case, we connect $\{\mathrm{E}, \mathrm{V}\}$ to $\{\mathrm{AR}, \mathrm{E}, \mathrm{V}\}$ and connect $\{\mathrm{AR}\}$ to $\{\mathrm{AR}, \mathrm{E}, \mathrm{V}\}$. These edges are drawn in Figure 2 in thin lines. Next, we determine $U_{1}$ and $H_{1}$ for the next iteration. We have $\mathrm{U}_{1}=\mathrm{U}_{0}-\mathrm{X}_{1}$, and $\mathrm{H}_{1}$ is the union of $\mathrm{F}_{1}$ and all the elements of $\mathrm{H}_{0}$ that do not contain $\mathrm{X}_{1}$. In the present case, we obtain $\mathrm{U}_{1}=\{\mathrm{E}, \mathrm{V}, \mathrm{CC}, \mathrm{CV}, \mathrm{SO}, \mathrm{SV}\}$, and $\mathrm{H}_{1}=\{\{\mathrm{CC}\},\{\mathrm{CV}\},\{\mathrm{SO}\},\{\mathrm{SV}\}$, $\{\mathrm{E}, \mathrm{V}\},\{\mathrm{CC}, \mathrm{CV}\},\{\mathrm{E}, \mathrm{CC}, \mathrm{SO}\},\{\mathrm{V}, \mathrm{CV}, \mathrm{SV}\}\}$. These are listed in column 4 of Exhibit 1 for $\mathrm{i}=1$.

\section{Iteration Two, $\mathbf{i}=\mathbf{2}$}

We repeat the above process for the second iteration. We again choose one variable at a time from $\mathrm{U}_{1}=\{\mathrm{E}, \mathrm{V}, \mathrm{CC}, \mathrm{CV}, \mathrm{SO}, \mathrm{SV}\}$ and determine the corresponding $\mathrm{G}_{2}$. As before, we obtain $\mathrm{G}_{2}$ by determining the union of all the elements of $\mathrm{H}_{1}$ that contain the variable. We pick the variable as $\mathrm{X}_{2}$ for which $\mathrm{G}_{2}$ has the least number of variables. In our case, if we choose $\mathrm{E}$ then $\mathrm{G}_{2}=\{\mathrm{E}, \mathrm{V}, \mathrm{CC}, \mathrm{SO}\}$, and if we choose $\mathrm{V}$ then $\mathrm{G}_{2}=\{\mathrm{E}, \mathrm{V}, \mathrm{CV}, \mathrm{SV}\}$. All $\mathrm{G}_{2}$ 's are given in column 2 in Exhibit 1 for $\mathrm{i}=2$. We have a two way tie between SO and SV for the least number of variables in $\mathrm{G}_{2}$. We choose $\mathrm{SO}$ because it is ahead of $\mathrm{SV}$ in the alphabetical order. Thus, $\mathrm{X}_{2}=$ $\{\mathrm{SO}\}, \mathrm{G}_{2}=\{\mathrm{E}, \mathrm{CC}, \mathrm{SO}\}$, and $\mathrm{F}_{2}=\{\mathrm{E}, \mathrm{CC}\}$.

The new nodes to be added in the second iteration are $\mathrm{G}_{2}, \mathrm{~F}_{2}$ and any element of $\mathrm{H}_{1}$ that contains $\mathrm{X}_{2}$ and is not equal to $\mathrm{G}_{2}$. In our case, the new nodes to be added are $\{\mathrm{E}, \mathrm{CC}, \mathrm{SO}\}$, $\{\mathrm{E}, \mathrm{CC}\}$, and $\{\mathrm{SO}\}$. These nodes are drawn in Figure 2 as ellipses with a boundary of medium thickness. The new edges to be added in this iteration are the edges between $\mathrm{G}_{2}$ and $\mathrm{F}_{2}$ and between $G_{2}$ and elements of $H_{1}$ that contain $X_{2}$ but not equal to $G_{2}$. Again, graphically it means that we connect $F_{2}$ to $G_{2}$, and the elements of $H_{1}$ containing $X_{2}$ (that are not equal to $G_{2}$ ) to $G_{2}$. These edges are drawn in Figure 2 with lines of medium thickness.

For the next iteration, we need $U_{2}$ and $H_{2}$. We know that $U_{2}=U_{1}-X_{2}$, and $H_{2}$ is obtained by determining the union of $\mathrm{F}_{2}$ with all the elements of $\mathrm{H}_{1}$ that do not contain $\mathrm{X}_{2}$. Thus, we have 
$\mathrm{U}_{2}=\{\{\mathrm{E}, \mathrm{V}, \mathrm{CC}, \mathrm{CV}, \mathrm{SV}\}\}$ and $\mathrm{H}_{2}=\{\{\mathrm{CC}\},\{\mathrm{CV}\},\{\mathrm{SV}\},\{\mathrm{E}, \mathrm{V}\},\{\mathrm{CC}, \mathrm{CV}\},\{\mathrm{V}, \mathrm{CV}, \mathrm{SV}\}$, $\{\mathrm{E}, \mathrm{CC}\}\}$

We repeat the above process five more times for $i=3$, to $i=7$. We stop at $i=7$ because $U_{7}$ and $\mathrm{H}_{7}$ become empty (see column 4 of Exhibit 1 for $\mathrm{i}=7$ ). The results of all seven iterations are given in Exhibit 1. The new nodes and edges added in each iteration are shown in Figure 2 with different kinds of lines for each iteration. Figure 2 represents one Markov tree for the evidential network in Figure 1. In the next section, we will describe the process of propagating beliefs in such a tree.

\section{PROPAGATION OF BELIEFS IN A MARKOV TREE}

Shenoy and Shafer (1986) have discussed the general approach for propagating beliefs (i.e., m-values) in a Markov tree using local computations (see, also, Shafer, Shenoy and Mellouli 1987; Shenoy and Shafer 1990). In this section, we illustrate the process using the Markov tree just constructed in Figure 2.

Before we describe the propagation process, we need to (1) define the frame of a variable, (2) discuss certain concepts, and (3) define some new symbols. A frame of a variable is defined to be the exhaustive and mutually exclusive set of possible values of the variable. We will use $\Theta$ to represent the frame. For example, the frame of the variable 'AR' representing the accounts receivable balance is $\Theta_{\mathrm{AR}}=\{\operatorname{ar}, \sim \operatorname{ar}\}$ where 'ar' represents that the accounts receivable balance is not materially misstated and ' ar' represents that the balance is materially misstated. As a general notation, we use the upper-case letter(s) to denote the name of a variable and lower-case letter(s) to denote its values.

The two concepts that are important for the propagation process are vacuous extension 6 , and marginalization 7 . When $\mathbf{m}$-values are sent from a smaller node (i.e., a node with fewer variables) to a bigger node (a node with more variables), the $\mathbf{m}$-values are vacuously extended onto the frame of the bigger node. When $\mathbf{m}$-values are sent from a bigger node to a smaller node, the $\mathbf{m}$-values are marginalized onto the frame of the smaller node. 
Regarding symbols, we will use $\mathbf{m}$ with an appropriate subscript to denote the $\mathbf{m}$-values at a node. For example, the $\mathbf{m}$-values at node 4 in Figure 3 based on Evidence 3 which is a test of controls will be denoted by $\mathbf{m}_{4 \mathrm{TC}}$. For the $\mathbf{m}$-values being sent from one node to another node, we will use a subscript with two numbers. The first number denotes one node and the second number denotes the other node, and an arrow in the middle denotes the direction of propagation. One should note that, in general, the $\mathbf{m}$-values being sent from one node to another node are the combination of $\mathbf{m}$-values defined at the sending node and the $\mathbf{m}$-values received from the neighboring nodes except from the one to which the resulting $\mathbf{m}$-values are being sent. For example, in Figure 3, $\mathbf{m}_{14 \varnothing 13}$ denotes the $\mathbf{m}$-values being sent from node 14 to node 13 and their values represent the combination of the $\mathbf{m}$-values coming from nodes 15 and 16 to node 14 and the $\mathbf{m}$-values defined at node 14 .

Figure 3 here

Figure 3 represents the Markov tree constructed in Figure 2 with the items of evidence connected to the respective nodes. In fact, Figure 3 is a Markov tree representation of the evidential network in Figure 1. We will use numerical examples to illustrate the propagation process. Since we are interested in determining the overall belief in 'ar' that the accounts receivable balance is not materially misstated, we follow the arrows in Figure 3 for propagating $\mathbf{m}$-values. Once we have constructed a Markov tree, the propagation process is straight forward but cumbersome. We will use the following sequence ${ }^{8}$ of steps to illustrate the propagation process. We begin from the top of the tree, node 4 in Figure 3. We bring all the $\mathbf{m}$-values from the top of the tree to node 7 , and bring all the $\mathbf{m}$-values from the bottom of the tree to node 7 , combine all the $\mathbf{m}$-values at node 7 , and propagate the resultant to node 3. Combine the $\mathbf{m}$-values obtained from node 7 with the $\mathbf{m}$-values at node 3 and propagate the resultant to node 2 . Next, combine the $\mathbf{m}$-values obtained from node 3 with the $\mathbf{m}$-values at node 2 , and propagate the resultant to node 1. This completes the propagation process of all the $\mathbf{m}$-values in the Markov tree to node 1 (see Figure 3). Combine the $\mathbf{m}$-values obtained from node 2 with the $\mathbf{m}$-values at node 1 . This 
process yields the total $\mathbf{m}$-values at node 1 as a result of aggregating all the $\mathbf{m}$-values in the network. Tables 2-6 give the details of the computations.

Table 2 here

Table 2 shows the steps involved in propagating the $\mathbf{m}$-values from node 4 to node 6 . The details of these steps are given below in the same order as the panels in Table 2 for each node.

- Combine the two sets of $\mathbf{m}$-values at node 4 , i.e., combine $\mathbf{m}_{4 T C}$, and $\mathbf{m}_{4 \mathrm{STT}}$ using Dempster's rule 9 . This process yields $\mathbf{m}_{4}^{\mathrm{t}}$. Using the numerical values for $\mathbf{m}_{4 \mathrm{TC}}$, and $\mathbf{m}_{4 \text { STT }}$ as given in Table 2, we obtain (see the first panel that corresponds to node 4 in Table 2):

$$
\mathbf{m}_{4}^{\mathrm{t}}(\mathrm{so})=0.88, \mathbf{m}_{4}^{\mathrm{t}}(\sim \mathrm{so})=0 \text {, and } \mathbf{m}_{4}^{\mathrm{t}}(\{\mathrm{so}, \sim \mathrm{so}\})=0.12 \text {. }
$$

- Propagate $\mathbf{m}$-values from node 4 to 5 . Since node 5 is a bigger node than node 4 , we vacuously extend $\mathbf{m}_{4}$ onto the frame of node 5 to obtain $\mathbf{m}_{4 \varnothing 5}$ (see Footnote 6 for vacuous extension). As discussed in Table 2 , the frame of node 5 is $\Theta_{5}=\{(\mathrm{e}, \mathrm{cc}, \mathrm{so}),(\sim \mathrm{e}, \mathrm{cc}, \sim \mathrm{so})$, ( e, $\sim \mathrm{cc}, \mathrm{so}),(\sim \mathrm{e}, \sim \mathrm{cc}, \sim \mathrm{so})\}$ (see the second footnote of Table 2$)$. The non-zero values of $\mathbf{m}_{4 \varnothing 5}$ are given as:

$$
\begin{gathered}
\mathbf{m}_{4 \varnothing 5}(\{(\mathrm{e}, \mathrm{cc}, \mathrm{so}),(\sim \mathrm{e}, \sim \mathrm{cc}, \mathrm{so})\})=\mathbf{m}_{4}^{\mathrm{t}}(\mathrm{so})=0.88 \\
\mathbf{m}_{4 \varnothing 5}\left(\Theta_{5}\right)=\mathbf{m}_{4}^{\mathrm{t}}(\{\mathrm{so}, \sim \mathrm{so}\})=0.12
\end{gathered}
$$

We combine the above $\mathbf{m}$-values with the $\mathbf{m}$-values defined at node 5 which is a vacuous belief function (i.e., $\left.\mathbf{m}_{5}\left(\Theta_{5}\right)=1.0\right)$. The resultant 10 non-zero $\mathbf{m}$-values are:

$$
\mathbf{m}_{5}^{\mathrm{t}}(\{(\mathrm{e}, \mathrm{cc}, \mathrm{so}),(\sim \mathrm{e}, \sim \mathrm{cc}, \mathrm{so})\})=0.88, \text { and } \mathbf{m}_{5}^{\mathrm{t}}\left(\Theta_{5}\right)=0.12 \text {. }
$$

- Propagate $\mathbf{m}_{5}{ }_{5}$ to node 6 . Since the frame of node $6, \Theta_{6}=\{(e, c c),(e, \sim c c),(\sim e, c c)$, $(\sim \mathrm{e}, \sim \mathrm{cc})\})$, is smaller than the frame of node 5 , we marginalize $\mathbf{m}^{\mathrm{t}}{ }_{5}$ onto $\Theta_{6}$ for propagation (see Footnote 7 for marginalization). Thus, the non-zero values of $\mathbf{m}_{5 \varnothing 6}$ are:

$$
\begin{gathered}
\mathbf{m}_{5 \varnothing 6}(\{(\mathrm{e}, \mathrm{cc}),(\sim \mathrm{e}, \sim \mathrm{cc})\})=\mathbf{m}_{5}^{\mathrm{t}}(\{(\mathrm{e}, \mathrm{cc}, \mathrm{so}),(\sim \mathrm{e}, \sim \mathrm{cc}, \mathrm{so})\})=0.88, \\
\mathbf{m}_{5 \varnothing 6}\left(\Theta_{6}\right)=\mathbf{m}_{5}^{\mathrm{t}}\left(\Theta_{5}\right)=0.12 .
\end{gathered}
$$


We combine the above $\mathbf{m}$-values with the $\mathbf{m}$-values defined at node 6 which is a vacuous belief function (i.e., $\mathbf{m}_{5}\left(\Theta_{6}\right)=1.0$ ). The resulting non-zero $\mathbf{m}$-values are (see Footnote 10):

$$
\mathbf{m}_{6}^{\mathrm{t}}(\{(\mathrm{e}, \mathrm{cc}),(\sim \mathrm{e}, \sim \mathrm{cc})\})=0.88 \text {, and } \mathbf{m}_{6}^{\mathrm{t}}\left(\Theta_{6}\right)=0.12 \text {. }
$$

Table 3 here

Table 3 presents the computations involved in propagating $\mathbf{m}$-values from the lower end of the Markov tree in Figure 3 to node 12. We do not present the details of these computations because they are similar to what we have already discussed for Table 2 above. However, we do describe the steps involved in the propagation process; one can compute the numbers from these details as given in Tables 3. The steps described below are in the same order as the panels in Table 3 for each node.

- First, combine the two sets of $\mathbf{m}$-values, $\mathbf{m}_{16 \mathrm{TC}}$ and $\mathbf{m}_{16 \mathrm{STT}}$, at node $16 . \mathbf{m}_{16 \mathrm{TC}}$ comes from Evidence 9 and $\mathbf{m}_{16 \mathrm{STT}}$ from Evidence 10. This process yields the total $\mathbf{m}$-values, $\mathbf{m}^{\mathrm{t}}{ }_{16}$, at node 16 (see the first panel of Table 3 corresponding to node 16).

- Determine the total $\mathbf{m}$-values at node 15 . In the present case, we have only one set of $\mathbf{m}$ values coming from Evidence 8 . This yields $\mathbf{m}^{\mathrm{t}}{ }_{15}$.

- Propagate $\mathbf{m}^{\mathrm{t}}{ }_{16}$ to node 14 by vacuously extending it onto the frame of node 14 . This process yields $\mathbf{m}_{16} \varnothing 14$. Propagate $\mathbf{m}^{\mathrm{t}}{ }_{15}$ to node 14 , again, by vacuously extending it onto the frame of node 14 . This process yields $\mathbf{m}_{15 \varnothing 14}$. Combine all the $\mathbf{m}$-values at node 14 , i.e., combine $\mathbf{m}_{16 \varnothing 14}, \mathbf{m}_{15 \varnothing 14}$, and $\mathbf{m}_{14}$. Since $\mathbf{m}_{14}$ is a vacuous belief function, the above combination is simply the combination of $\mathbf{m}_{16 \varnothing 14}$ and $\mathbf{m}_{15 \varnothing 14}$ which yields $\mathbf{m}_{14}$.

- Propagate $\mathbf{m}^{\mathrm{t}}{ }_{14}$ to node 13 by vacuously extending it onto the fame of node 13 . Combine $\mathbf{m}_{14 \varnothing 13}$ with $\mathbf{m}_{13}$ and obtain $\mathbf{m}^{\mathrm{t}}{ }_{13}$. Again, since $\mathbf{m}_{13}$ is a vacuous belief function, $\mathbf{m}^{\mathrm{t}}{ }_{13}$ is simply $\mathbf{m}_{14 \varnothing 13}$. 
- Propagate $\mathbf{m}_{13}^{\mathrm{t}}$ to node 12 by marginalizing it onto the frame of node 12 . This yields $\mathbf{m}_{13 \varnothing 12}$. Now, we combine $\mathbf{m}_{13 \varnothing 12}$ with $\mathbf{m}_{12}$ to obtain $\mathbf{m}^{t}{ }_{12}$ for the next step. Again, $\mathbf{m}_{12}$ is a vacuous belief function, therefore $\mathbf{m}^{t}{ }_{12}$ is the same as $\mathbf{m}_{13 \varnothing 12}$.

\section{Table 4 here}

Table 4 represents the propagation of the m-values from nodes 10,11 and 12 to node 9 . The following steps explain the propagation process. Again, we present the steps below in the same order as the panels in Table 4 for each node.

- Determine the total $\mathbf{m}$-values at node $11, \mathbf{m}^{\mathrm{t}}{ }_{11}$, by combining the two $\mathbf{m}$-values at node 11, one from Evidence $5\left(\mathbf{m}_{11 \mathrm{TC}}\right)$ and the other from Evidence $6\left(\mathbf{m}_{11 \mathrm{STT}}\right)$.

- Determine the total $\mathbf{m}$-values at node 10 . Since we have only one set of $\mathbf{m}$-values, $\mathbf{m}_{10 \mathrm{STT}}$, at node 10 corresponding to Evidence $7, \mathbf{m}^{\mathrm{t}} 10$ is simply $\mathbf{m}_{10 \mathrm{STT}}$.

- Propagate $\mathbf{m}^{\mathrm{t}}{ }_{11}, \mathbf{m}^{\mathrm{t}}{ }_{10}$ and $\mathbf{m}_{12}^{\mathrm{t}}$ to node 9 . As we know, node 9 is a bigger node than any of the nodes 10,11 or 12 . Therefore, we vacuously extend $\mathbf{m}_{11}^{\mathrm{t}}, \mathbf{m}^{\mathrm{t}}{ }_{10}$ and $\mathbf{m}^{\mathrm{t}}{ }_{12}$ onto the frame of node 9 . This process yields $\mathbf{m}_{10 \varnothing 9}, \mathbf{m}_{11 \varnothing 9}$, and $\mathbf{m}_{12 \varnothing 9}$. Next, combine $\mathbf{m}_{10 \varnothing 9}$, $\mathbf{m}_{11 \varnothing 9}$, and $\mathbf{m}_{12 \varnothing 9}$ with $\mathbf{m}_{9}$ to obtain $\mathbf{m}_{9}{ }_{9}$ at node 9 . Since $\mathbf{m}_{9}$ is a vacuous belief function, we need to combine only $\mathbf{m}_{10 \varnothing 9}, \mathbf{m}_{11 \varnothing 9}$, and $\mathbf{m}_{12 \varnothing 9}$. This step yields $\mathbf{m}_{9}{ }_{9}$.

\section{Table 5 here}

Table 5 deals with the computations involving propagation of $\mathbf{m}$-values from nodes 6 and 8 to node 7. The first panel of Table 5 provides the values of $\mathbf{m}_{9 \varnothing 8}$ and $\mathbf{m}_{8}{ }_{8}$. Since node 8 is a smaller node compared to node 9 , we marginalize $\mathbf{m}_{9}{ }_{9}$ onto $\Theta_{8}$ to obtain $\mathbf{m}_{9 \varnothing 8}$. We combine $\mathbf{m}_{9 \varnothing 8}$ with $\mathbf{m}_{8}$ to obtain $\mathbf{m}_{8}{ }_{8}$. The second panel of Table 5 represents the propagation of $\mathbf{m}-$ values from nodes 8 and 6 which yields $\mathbf{m}^{t_{7}}$.

\section{Table 6 here}

Table 6 presents the computations relevant to the propagation of $\mathbf{m}$-values from node 7 to node 1. The steps described below are in the same order as the panels in Table 6 for each node: 
- Propagate $\mathbf{m}_{7}$ to node 3 by marginalizing it onto $\Theta_{3}$. This process yields $\mathbf{m}_{7 \varnothing 3}$. Combine $\mathbf{m}_{7 \varnothing 3}$ with $\mathbf{m}_{3}$ to obtain $\mathbf{m}_{3}$.

- Propagate $\mathbf{m}_{3}{ }_{3}$ to node 2 by vacuously extending it onto $\Theta_{2}$. Combine the resulting $\mathbf{m}$ values with $\mathbf{m}_{2}$ to yield $\mathbf{m}_{2}$.

- Propagate $\mathbf{m}_{2}{ }_{2}$ to node 1 by marginalizing it onto the frame of node 1 . This yields $\mathbf{m}_{2 \varnothing 1}$. Combine $\mathbf{m}_{2 \varnothing 1}$ with $\mathbf{m}_{1 \mathrm{IF}}$ (Evidence 1) and $\mathbf{m}_{1 \mathrm{AP}}$ (Evidence 2). This yields $\mathbf{m}^{\mathrm{t}}{ }_{1}$ which represents the combination of all the evidence in the network in Figure 1 at node 1.

The above process completes the aggregation of all the evidence in the network in Figure 1. In the present article, we have illustrated the propagation of beliefs in only one direction; the direction that yields the overall belief for node 1 . However, one can use the same procedure of propagating beliefs if we were interested in the overall belief in any other variable. For example, if we want to find the overall belief in variable SO then all the $\mathbf{m}$-values in the Markov tree in Figure 3 will have to flow towards node 4 . It is extremely cumbersome to calculate the overall belief for each variable in the network in Figure 1 without the help of a computer. As mentioned earlier, Shafer, Shenoy, and Srivastava (1988) have developed such a computer system that automates the propagation process (also, see Srivastava, Shenoy, and Shafer 1990). 


\section{DISCUSSION OF THE RESULTS}

We have used numerical inputs for the strength of each item of evidence in Figure 1 as given in Tables 2-6. These inputs are based on the auditor's judgment. We believe that the auditor is more comfortable in thinking of the strength of evidence in terms of belief functions. ${ }^{13}$ Of course, an empirical study is needed to find out how an auditor thinks.

After aggregating all the evidence in the network in Figure 1, the overall $\mathbf{m}$-values at node 1 is given by (see the last panel of Table 6):

$$
\mathbf{m}^{\mathrm{t}}{ }_{\mathrm{AR}}(\operatorname{ar})=0.95307, \mathbf{m}_{\mathrm{AR}}^{\mathrm{t}}(\sim \operatorname{ar})=0, \text { and } \mathbf{m}_{\mathrm{AR}}^{\mathrm{t}}(\{\operatorname{ar}, \sim \operatorname{ar}\})=0.04693 .
$$

The corresponding beliefs and plausibilities are given by (see Srivastava and Shafer 1992 for definitions):

$$
\text { Belt }_{\mathrm{AR}}(\operatorname{ar})=0.95307, \mathbf{B e l}_{\mathrm{AR}}^{\mathrm{t}}(\sim \operatorname{ar})=0, \text { and } \mathbf{B e l}_{\mathrm{AR}}^{\mathrm{t}}(\{\operatorname{ar}, \sim \operatorname{ar}\})=1,
$$

and

$$
\mathbf{P L}_{\mathrm{AR}}^{\mathrm{t}}(\operatorname{ar})=1-\mathbf{B e l}_{\mathrm{AR}}^{\mathrm{t}}(\sim \operatorname{ar})=1 \text {, and } \mathbf{P L}_{\mathrm{AR}}^{\mathrm{t}}(\sim \operatorname{ar})=1-\mathbf{B e l}_{\mathrm{AR}}^{\mathrm{t}}(\operatorname{ar})=0.04693 .
$$

The above results indicate that we have an overall belief of 0.95307 that the accounts receivable balance is not materially misstated and a plausibility 0.04693 that the account is materially misstated. As discussed by Shafer and Srivastava (1992), plausibility in ' ar' is equivalent to the audit risk. Thus, we have 0.04693 risk that the account is materially misstated. The plausibility that the account is not materially misstated is 1 because we have no belief in support of material misstatement of the account. An intuitive interpretation of this is that if we had to collect more evidence then the belief in 'ar' could increase to 1 from 0.95307 .

\section{SUMMARY AND CONCLUSION}

We have illustrated the belief-function approach to aggregating audit evidence. In general, aggregating evidence in the belief-function framework is essentially propagating beliefs in the evidential network. We have discussed the three steps involved in the aggregation process. The first step deals with constructing the evidential network for the audit and identifying the clusters of variables over which we have belief functions. The second step deals with constructing a 
Markov tree from the evidential network. The third step deals with propagating beliefs (i.e., mvalues) from all other nodes in the Markov tree to the node in which we are interested. We have used a moderately complex example to show the details of the aggregation process.

There are several questions related to assessment of beliefs in the audit evidence which are not dealt with in this article. For example, what is the level of belief the auditor assigns to a subjective item of evidence such as analytical procedures or inherent factors related to the client or the industry? What are the factors that determine the strength of evidence in such cases? What is the level of belief obtained from statistical evidence? What should be the sample size for a statistical test to obtain a desired level of belief? These questions are important and require further research.

Further, we should point out that the use of 'and' relationships in our numerical example is purely for simplicity of computations. The approach discussed here is a general approach and it is valid for other relationships too. There is no difference in the mechanics of the propagation process. We will have the same cluster of variables and the same Markov tree. The only difference will be in the belief function that defines the relationship. We have two major concerns regarding using the 'and' relationship in an evidential network. One, that the 'and' relationship treats all the variables on the right of the node in the network with equal importance. For example, if an account is connected to all its audit objectives through an 'and' node then each audit objective is equally important. But this may not be true, in general, in the auditing context; one audit objective may be more important than the other.

The second concern is that the 'and' relationship is symmetric and may not very well represent the relationship between a balance sheet item and items on the income statement. For example, if we know with certainty that sales have occurred and cash receipts are complete then we definitely know that the existence objective of accounts receivable has been met (see Footnote 4). But the reverse is not necessarily true. That is, if we know with certainty that the existence objective of accounts receivable has been met then we are not able to conclude with the same 
level of confidence that sales have occurred and cash receipts are complete. We need both theoretical and empirical study to model these relationships in belief functions. 


\section{FOOTNOTES}

1. The evidential structure is a tree when each item of evidence relates to only one account or only one audit objective of an account. This structure changes into a network when an item of evidence relates to more than one account or audit objective of an account. An example of such an item of evidence is the confirmation of accounts receivable which relates to both valuation and existence objectives of the account.

2. An affirmative item of evidence means that we have assurance in favor of the account being not materially misstated or the audit objective being met and no assurance for the negation.

3. An example of the 'and' relationship is that the accounts receivable account is not materially misstated if and only if all the audit objectives of the account have been satisfied. This relationship makes all the audit objectives equally important. Similarly, an 'and' relationship between the financial statements and the accounts implies that the financial statements are fairly presented if and only if all the accounts are not materially misstated. This relationship again makes all the accounts equally important.

4. We have assumed that sales returns and cash discounts are not material.

5. The choice based on the alphabetical order is purely a personal preference, one can choose any variable that yields the appropriate $G$. The Markov tree may look different but the final propagation of beliefs will be the same in all cases (Shenoy and Shafer 1990). It should be noted that in the case of a tie we have chosen a variable with a one-letter name over a variable with a two-letter name.

6. Vacuous Extension: Whenever a set of $\mathbf{m}$-values is propagated from a smaller node (fewer variables) to a bigger node (more variables), the $\mathbf{m}$-values are said to be vacuously extended onto the frame of the bigger node. As an illustration, suppose we have the following $\mathbf{m}$ values on node $\mathrm{E}$ with frame $\Theta_{\mathrm{E}}=\{\mathrm{e}, \sim \mathrm{e}\}$.

$$
\mathbf{m}_{\mathrm{E}}(\mathrm{e})=0.75, \mathbf{m}_{\mathrm{E}}(\sim \mathrm{e})=0, \mathbf{m}_{\mathrm{E}}(\{\mathrm{e}, \sim \mathrm{e}\})=0.25
$$

We want to vacuously extend them to a bigger node consisting of objectives $\mathrm{E}$ and $\mathrm{V}$. The entire frame of this combined node is obtained by multiplying the two individual frames, $\Theta_{\mathrm{E}}$ $=\{\mathrm{e}, \sim \mathrm{e}\}$ and $\Theta_{\mathrm{V}}=\{\mathrm{v}, \sim \mathrm{v}\}$. The resulting frame is $\Theta_{\mathrm{E}, \mathrm{V}}=\Theta_{\mathrm{E}} \mathrm{x} \Theta_{\mathrm{V}}=\{(\mathrm{e}, \mathrm{v}),(\mathrm{e}, \sim \mathrm{V}),(\sim \mathrm{e}, \mathrm{v})$, $(\sim \mathrm{e}, \sim \mathrm{v})\}$. The vacuous extension of the above $\mathbf{m}$-values from frame $\Theta_{\mathrm{E}}=\{\mathrm{e}, \sim \mathrm{e}\}$ to frame $\Theta_{\mathrm{E}, \mathrm{V}}$ is as follows:

$$
\begin{gathered}
\mathbf{m}(\{(\mathrm{e}, \mathrm{v}),(\mathrm{e}, \sim \mathrm{v})\})=\mathbf{m}_{\mathrm{E}}(\mathrm{e})=0.75 \\
\mathbf{m}\left(\Theta_{\mathrm{E}, \mathrm{V}}\right)=\mathbf{m}_{\mathrm{E}}\left(\Theta_{\mathrm{E}}\right)=0.25
\end{gathered}
$$

and $\mathbf{m}$-values for other subsets of $\Theta_{\mathrm{E}, \mathrm{V}}$ are zero.

7. Marginalization: Propagating $\mathbf{m}$-values from a bigger node to a smaller node is called marginalization. Let us consider the above example of Footnote 6 with slightly different $\mathbf{m}$ values. Suppose we have the following $\mathbf{m}$-values at $\Theta_{\mathrm{E}, \mathrm{V}}$ which is the frame of the combined nodes $\mathrm{E}$ and $\mathrm{V}$ :

$$
\mathbf{m}(\mathrm{e}, \mathrm{v})=0.4
$$


all other $\mathbf{m}$-values are zero.

$$
\begin{gathered}
\mathbf{m}(\{(\mathrm{e}, \mathrm{v}),(\mathrm{e}, \sim \mathrm{v})\})=0.2 \\
\mathbf{m}\left(\Theta_{\mathrm{E}, \mathrm{V}}\right)=0.4
\end{gathered}
$$

Let us first marginalize onto the frame $\Theta_{\mathrm{E}}=\{\mathrm{e}, \sim \mathrm{e}\}$. Similar to marginalization of probabilities, we will sum all the $\mathbf{m}$-values over the elements of frame $\Theta_{\mathrm{V}}=\{\mathrm{v}, \sim \mathrm{V}\}$ for a given set of elements of frame $\Theta_{\mathrm{E}}=\{\mathrm{e}, \sim \mathrm{e}\}$, i.e.,

$$
\begin{gathered}
\mathbf{m}(\mathrm{e})=\mathbf{m}(\mathrm{e}, \mathrm{v})+\mathbf{m}(\{(\mathrm{e}, \mathrm{v}),(\mathrm{e}, \sim \mathrm{v})\})=0.4+0.2=0.6 \\
\mathbf{m}(\sim \mathrm{e})=0, \\
\mathbf{m}(\{\mathrm{e}, \sim \mathrm{e}\})=\mathbf{m}\left(\Theta_{\mathrm{E}, \mathrm{V}}\right)=0.4 .
\end{gathered}
$$

Marginalizing onto the frame $\Theta_{\mathrm{V}}=\{\mathrm{v}, \sim \mathrm{V}\}$ yields the following values:

$$
\begin{gathered}
\mathbf{m}(\mathrm{v})=\mathbf{m}(\mathrm{e}, \mathrm{v})=0.4 \\
\mathbf{m}(\sim \mathrm{v})=0, \\
\mathbf{m}(\{\mathrm{v}, \sim \mathrm{v}\})=\mathbf{m}(\{(\mathrm{e}, \mathrm{v}),(\mathrm{e}, \sim \mathrm{v})\})+\mathbf{m}\left(\Theta_{\mathrm{E}, \mathrm{V}}\right) \\
=0.2+0.4=0.6 .
\end{gathered}
$$

8. There are several sequences of the same steps. One could begin from the lower end of the tree in Figure 3, propagate all the $\mathbf{m}$-values to node 7, and bring all the $\mathbf{m}$-values from the top of the tree to node 7, combine all these $\mathbf{m}$-values at node 7 . Finally, propagate the $\mathbf{m}$-values from nodes 7,3 , and 2 to node 1 . The final result will be the same irrespective of the starting point.

9. If we have two independent items of evidence with $\mathbf{m}_{1}$ and $\mathbf{m}_{2}$ representing the $\mathbf{m}$-values on a frame $\Theta$ then by Dempster's rule (Shafer 1976) we obtain the combined $\mathbf{m}$-value for a subset $\mathrm{A}$ of frame $\Theta$ as

$$
\mathbf{m}(\mathrm{A})=\mathrm{K}^{-1} \Sigma\left\{\mathbf{m}_{1}\left(\mathrm{~B}_{1}\right) \mathbf{m}_{2}\left(\mathrm{~B}_{2}\right) \mid \mathrm{B}_{1} \leftrightarrow \mathrm{B}_{2}=\mathrm{A}, \mathrm{A} \neq \varnothing\right\}
$$

where the renormalization constant, $\mathrm{K}$, is given by

$$
\mathrm{K}=1-\Sigma\left\{\mathbf{m}_{1}\left(\mathrm{~B}_{1}\right) \mathbf{m}_{2}\left(\mathrm{~B}_{2}\right) \mid \mathrm{B}_{1} \leftrightarrow \mathrm{B}_{2}=\right\}
$$

The second term in $\mathrm{K}$ represents the conflict between the two items of evidence. If the two items of evidence exactly contradict each other, i.e., if $\mathrm{K}=0$ then the two items of evidence are not combinable. In other words, we cannot use Dempster's rule when $\mathrm{K}=0$. See Shafer (1976) for more than two independent items of evidence.

10. When a belief function on a frame is combined with a vacuous belief function on the frame, the combined belief function is the same as the original belief function. For example, if we have a belief function on the frame $\Theta_{\mathrm{AR}}=\{\operatorname{ar}, \sim \operatorname{ar}\}$ as: $\mathbf{m}_{1}(\operatorname{ar})>0, \mathbf{m}_{1}(\sim \operatorname{ar})>0$, and $\mathbf{m}_{1}(\{\operatorname{ar}$, $\sim \operatorname{ar}\})>0$. Suppose we have a vacuous belief function on the same frame, i.e., $\mathbf{m}_{2}(\operatorname{ar})=0$, $\mathbf{m}_{2}(\sim \operatorname{ar})=0$, and $\mathbf{m}_{2}(\{\operatorname{ar}, \sim \operatorname{ar}\})=1$. Using Dempster's rule to combine the two beliefs, we obtain the resultant belief to be: $\mathbf{m}(\operatorname{ar})=\mathbf{m}_{1}(\operatorname{ar}), \mathbf{m}(\sim \operatorname{ar})=\mathbf{m}_{1}(\sim \operatorname{ar})$, and $\mathbf{m}(\{\operatorname{ar}, \sim \operatorname{ar}\})=$ $\mathbf{m}_{1}(\{\mathrm{ar}, \sim \operatorname{ar}\})$ which implies that the original belief has been unaffected by combining a vacuous belief function. 
11. We want to combine $\mathbf{m}_{16 \varnothing 14}, \mathbf{m}_{15 \varnothing 14}$ and $\mathbf{m}_{14}$ to obtain $\mathbf{m}^{\mathrm{t}}{ }_{14}$ using Dempster's rule. Since $\mathbf{m}_{14}$ is a vacuous belief function, $\mathbf{m}^{\mathrm{t}}{ }_{14}$ will be simply the combination of $\mathbf{m}_{16 \varnothing 14}$ and $\mathbf{m}_{15 \varnothing 14}$. We have the following non-zero values of $\mathbf{m}_{16 \varnothing 14}$ and $\mathbf{m}_{15 \varnothing 14}$ as (see Table 3):

$$
\begin{gathered}
\mathbf{m}_{16 \varnothing 14}(\{(\mathrm{cv}, \mathrm{sv}),(\sim \mathrm{cv}, \mathrm{sv})\})=0.88, \\
\mathbf{m}_{16 \varnothing 14}\left(\Theta_{14}\right)=0.12,
\end{gathered}
$$

and

$$
\begin{gathered}
\mathbf{m}_{15 \varnothing 14}(\{(\mathrm{cv}, \mathrm{sv}),(\mathrm{cv}, \sim \mathrm{sv})\})=0.6 \\
\mathbf{m}_{15 \varnothing 14}\left(\Theta_{14}\right)=0.4 .
\end{gathered}
$$

Using Dempster's rule (see Footnote 9), we find that there is no conflict between the two mvalues, i.e., $\mathrm{K}=1$. Therefore, we obtain:

$\mathbf{m}^{\mathrm{t}}{ }_{14}(\mathrm{cv}, \mathrm{sv})=\mathbf{m}_{16 \varnothing 14}(\{(\mathrm{cv}, \mathrm{sv}),(\sim \mathrm{cv}, \mathrm{sv})\}) \mathbf{m}_{15 \varnothing 14}(\{(\mathrm{cv}, \mathrm{sv}),(\mathrm{cv}, \sim \mathrm{sv})\})=0.88 \mathrm{x} 0.6=0.528$, $\mathbf{m}^{\mathrm{t}}{ }_{14}(\{(\mathrm{cv}, \mathrm{sv}),(\sim \mathrm{cv}, \mathrm{sv})\})=\mathbf{m}_{16} \varnothing 14(\{(\mathrm{cv}, \mathrm{sv}),(\sim \mathrm{cv}, \mathrm{sv})\}) \mathbf{m}_{15 \varnothing 14}\left(\Theta_{14}\right)=0.88 \mathrm{x} 0.4=0.352$, $\mathbf{m}^{\mathrm{t}}{ }_{14}(\{(\mathrm{cv}, \mathrm{sv}),(\mathrm{cv}, \sim \mathrm{sv})\})=\mathbf{m}_{16 \varnothing 14}\left(\Theta_{14}\right) \mathbf{m}_{15 \varnothing 14}(\{(\mathrm{cv}, \mathrm{sv}),(\mathrm{cv}, \sim \mathrm{sv})\})=0.12 \mathrm{x} 0.6=0.072$

$$
\mathbf{m}_{14}\left(\Theta_{14}\right)=\mathbf{m}_{16 \varnothing 14}\left(\Theta_{14}\right) \mathbf{m}_{15 \varnothing 14}\left(\Theta_{14}\right)=0.12 \times 0.4=0.048 \text {. }
$$

12. We want to combine $\mathbf{m}_{10 \varnothing 9}, \mathbf{m}_{11 \varnothing 9}$, and $\mathbf{m}_{12 \varnothing 9}$ to obtain $\mathbf{m}_{9}^{t}$. We have the following values for them (see Table 4):

$$
\begin{gathered}
\mathbf{m}_{11 \varnothing 9}(\{(\mathrm{v}, \mathrm{cc}, \mathrm{cv}),(\mathrm{v}, \mathrm{cc}, \sim \mathrm{cv}),(\sim \mathrm{v}, \mathrm{cc}, \mathrm{cv}),(\sim \mathrm{v}, \mathrm{cc}, \sim \mathrm{cv})\})=0.88, \text { and } \mathbf{m}_{11 \varnothing 9}\left(\Theta_{9}\right)=0.12 \\
\mathbf{m}_{10 \varnothing 9}(\{(\mathrm{v}, \mathrm{cc}, \mathrm{cv}),(\sim \mathrm{v}, \mathrm{cc}, \mathrm{cv})\})=0.7, \text { and } \mathbf{m}_{10 \varnothing 9}\left(\Theta_{9}\right)=0.3 \\
\mathbf{m}_{12 \varnothing 9}(\{(\mathrm{v}, \mathrm{cc}, \mathrm{cv}),(\mathrm{v}, \sim \mathrm{cc}, \mathrm{cv})\})=0.528 \\
\mathbf{m}_{12 \varnothing 9}(\{(\mathrm{v}, \mathrm{cc}, \mathrm{cv}),(\mathrm{v}, \sim \mathrm{cc}, \mathrm{cv}),(\sim \mathrm{v}, \mathrm{cc}, \sim \mathrm{cv}),(\sim \mathrm{v}, \sim \mathrm{cc}, \sim \mathrm{cv})\})=0.352 \\
\mathbf{m}_{12 \varnothing 9}(\{(\mathrm{v}, \mathrm{cc}, \mathrm{cv}),(\mathrm{v}, \sim \mathrm{cc}, \mathrm{cv}),(\sim \mathrm{v}, \mathrm{cc}, \mathrm{cv}),(\sim \mathrm{v}, \sim \mathrm{cc}, \mathrm{cv})\})=0.072 \\
\mathbf{m}_{12 \varnothing 9}\left(\Theta_{9}\right)=0.048 .
\end{gathered}
$$

It is easier to combine three sets of $\mathbf{m}$-values in steps. First, we combine $\mathbf{m}_{10 \varnothing 9}$ and $\mathbf{m}_{11 \varnothing 9}$ which yields, say $\mathbf{m}_{9}$. Next, we combine $\mathbf{m}_{9}{ }_{9}$ with $\mathbf{m}_{12 \varnothing 9}$ that yields $\mathbf{m}_{9}{ }_{9}$. Using Dempster's rule to combine $\mathbf{m}_{10 \varnothing 9}$ and $\mathbf{m}_{11 \varnothing 9}$, we obtain the following non-zero values:

$$
\begin{aligned}
& \mathbf{m}_{9}^{\prime}(\{(\mathrm{v}, \mathrm{cc}, \mathrm{cv}),(\sim \mathrm{v}, \mathrm{cc}, \mathrm{cv})\})=\mathbf{m}_{10 \varnothing 9}(\{(\mathrm{v}, \mathrm{cc}, \mathrm{cv}),(\sim \mathrm{v}, \mathrm{cc}, \mathrm{cv})\}) \\
& \quad \mathrm{x}\left[\mathbf{m}_{11 \varnothing 9}(\{(\mathrm{v}, \mathrm{cc}, \mathrm{cv}),(\mathrm{v}, \mathrm{cc}, \sim \mathrm{cv}),(\sim \mathrm{v}, \mathrm{cc}, \mathrm{cv}),(\sim \mathrm{v}, \mathrm{cc}, \sim \mathrm{cv})\})+\mathbf{m}_{11 \varnothing 9}\left(\Theta_{9}\right)\right] \\
& \quad=0.7(0.88+0.12)=0.7, \\
& \mathbf{m}_{9}^{\prime}(\{(\mathrm{v}, \mathrm{cc}, \mathrm{cv}),(\mathrm{v}, \mathrm{cc}, \sim \mathrm{cv}),(\sim \mathrm{v}, \mathrm{cc}, \mathrm{cv}),(\sim \mathrm{v}, \mathrm{cc}, \sim \mathrm{cv})\}) \\
& =\mathbf{m}_{10 \varnothing 9}\left(\Theta_{9}\right) \mathbf{m}_{11 \varnothing 9}(\{(\mathrm{v}, \mathrm{cc}, \mathrm{cv}),(\mathrm{v}, \mathrm{cc}, \sim \mathrm{cv}),(\sim \mathrm{v}, \mathrm{cc}, \mathrm{cv}),(\sim \mathrm{v}, \mathrm{cc}, \sim \mathrm{cv})\}) \\
& =0.3 \mathrm{x} 0.88=0.264, \\
& \mathbf{m}_{9}^{\prime}\left(\Theta_{9}\right)= \\
& \mathbf{m}_{10 \varnothing 9}\left(\Theta_{9}\right) \mathbf{m}_{11 \varnothing 9}\left(\Theta_{9}\right)=0.3 \mathrm{x} 0.12=0.036 .
\end{aligned}
$$

We now combine $\mathbf{m}_{9}^{\prime}$ and $\mathbf{m}_{12 \varnothing 9}$. The following are the non-zero values of $\mathbf{m}_{9}{ }_{9}$ (in terms of the above equations):

$\mathbf{m}_{9}^{\mathrm{t}}(\mathrm{v}, \mathrm{cc}, \mathrm{cv})=(1)(5)+(1)(6)+(2)(5)$

$=\mathbf{m}_{12 \varnothing 9}(\{(\mathrm{v}, \mathrm{cc}, \mathrm{cv}),(\mathrm{v}, \sim \mathrm{cc}, \mathrm{cv})\}) \mathbf{m}_{9}^{\prime}(\{(\mathrm{v}, \mathrm{cc}, \mathrm{cv}),(\sim \mathrm{v}, \mathrm{cc}, \mathrm{cv})\})$ 


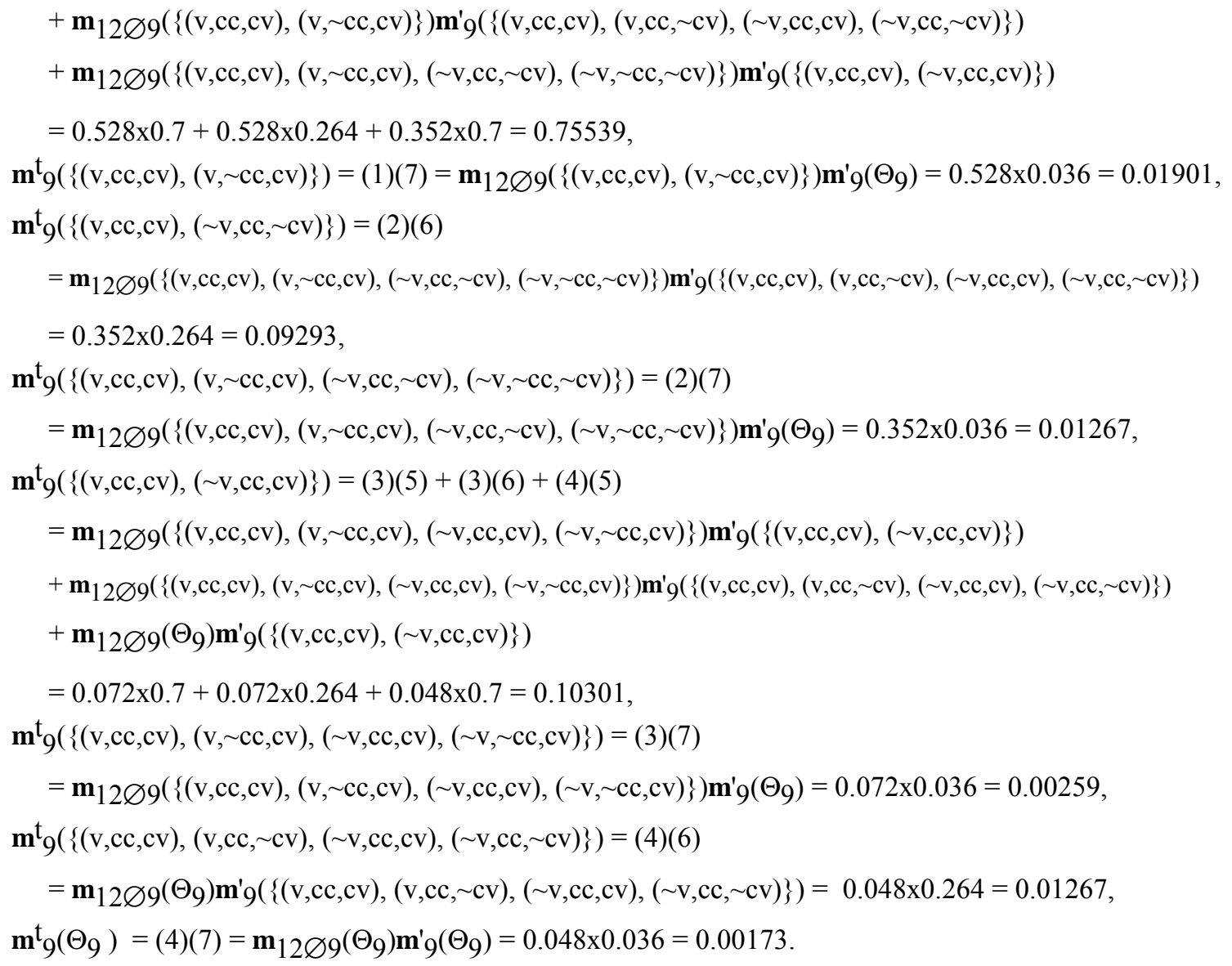

13. Although it is an empirical question, our experience with talking to several experienced auditors of various accounting firms suggests that the auditors feel that when dealing with audit evidence, it is more intuitive to think in terms of belief functions than to think of probabilities. For example, suppose the auditor has been involved with the client for several years and has very positive feelings about the management, and also does not see any problem with the industry. Hence, a positive feeling about the fair presentation of the overall financial statements. But, he is not willing to put too much weight on this evidence (or combination of evidence). It is more intuitive for him to say that he believes that the financial statements are fairly presented with a low level of assurance, say 0.3 , and for the remaining belief of 0.7 he does not know what to do; it is definitely not in support of the material misstatement. He will have to gather more evidence to reallocate 0.7 . Representing the above evidence in probability terms does not quite express the auditor's feeling. 
Srivastava, Rajendra. (1995) The Belief-Function Approach to Aggregating Audit Evidence. International Journal of Intelligent

Systems, 10 (3), 329-356. Publisher's Official Version: <http://onlinelibrary.wiley.com/journal/10.1002/\%28ISSN\%291098-111X>.

Open Access Version: <http://kuscholarworks.ku.edu/dspace/>.

\section{REFERENCES}

Akresh, A. D., J. K. Loebbecke, and W. R. Scott, "Audit Approaches and Techniques," in Research Opportunities in Auditing: The Second Decade, Edited by A. Rashad Abdelkhalik and Ira Solomon (American Accounting Association 1988) pp. 13-55.

Arens, A. A., and J. K. Loebbecke, AUDITING: An Integrated Approach, (New Jersey: Prentice Hall, Inc. 1991).

Dutta, S. K., and R. P. Srivastava, "Aggregation of Evidence in Auditing: A Likelihood Perspective," Auditing: A Journal of Practice and Theory (Supplement 1993, forthcoming). The paper was also presented at the USC Audit Judgment Symposium, February 1992.

Kong, A, Multivariate belief functions and graphical models, Doctoral Dissertation (Harvard University 1986).

Leslie, D. A., S. J. Aldersley, D. J. Cockburn, and C. J. Reiter, "An Assertion Based Approach to Auditing (Discussant's Remarks)," Proceedings of the 1986 Touche Ross/University of Kansas Symposium on Auditing Problems (May 1986) pp. 31-68.

Maier, D., The Theory of Relational Databases, Computer Press (1983).

Mellouli, K., "On the Propagation of Beliefs in Networks Using the Dempster-Shafer Theory of Evidence," Doctoral dissertation (School of Business, University of Kansas 1987).

Shafer, G., A Mathematical Theory of Evidence, (Princeton University Press 1976).

Shafer, G., P. P. Shenoy and K. Mellouli, "Propagating Belief Functions in Qualitative Markov Trees," International Journal of Approximate Reasoning, Vol. 1 (1987) pp. 349-400.

Shafer, G., P. P. Shenoy, and R. P. Srivastava, "AUDITOR'S ASSISTANT: A Knowledge Engineering Tool For Audit Decisions," Proceedings of the 1988 Touche Ross/University of Kansas Symposium on Auditing Problems (May 1988) pp. 61-84.

Shafer, G., and R. P. Srivastava, "The Bayesian and Belief-Function Formalisms-A General Perspective For Auditing," Auditing: A Journal of Practice and Theory (Supplement, 1990) pp. 110-148.

Shenoy, P. P., "Valuation-Based System for Discrete Optimization," in Uncertainty in Artificial Intelligence, Vol. 6 (North-Holland, Amsterdam), edited by P.P. Bonissone, M. Henrion, L. N. Kanal, and J. Lemmer (1991) pp. 385-400.

Shenoy, P. P. and G. Shafer, "Propagating Belief Functions with Local Propagation," IEEE Expert, Vol. 1 (1986) pp. 43-52.

Shenoy, P. P., and G. Shafer, "Axioms for Probability and Belief-Function Computation," In Shachter, R. D., T. S. Levitt, J. F. Lemmer, and L. N. Kanal, eds., Uncertainty in Artificial Intelligence, 4 (North-Holland 1990) pp. 169-198. 
Srivastava, R.P., "A General Scheme for Aggregating Evidence in Auditing: Propagation of Beliefs in Networks," Artificial Intelligence in Accounting and Auditing, Vol. 2, Miklos A. Vasarhelyi, editor, Markus Wiener Publishers, 1993 (forthcoming).

Srivastava, R. P., and R. Johns, “ An Expert System Approach to Audit Planning and Evaluation in the Belief-Function Framework," Presented at the 1993 American Accounting Association Workshop on AI/ES in Accounting, Auditing and Tax, Washington, DC., August 1992. This paper was also presented at the Conference on Expert Systems in Auditing, Accounting and Telecommunications, Rutgers University, Newark, November 20-21, 1992 (invited)

Srivastava, R. P., and G. Shafer, "Belief-Function Formulas for Audit Risk," The Accounting Review (April 1992) pp. 249-83.

Srivastava, R. P., P. P. Shenoy and G. Shafer, "Belief Propagation in Networks for Auditing," at the 1990 University of Southern California Audit Judgment Symposium, February 19-20, 1990. 


\section{Figure 1}

\section{Evidential Network for Accounts Receivable*.}

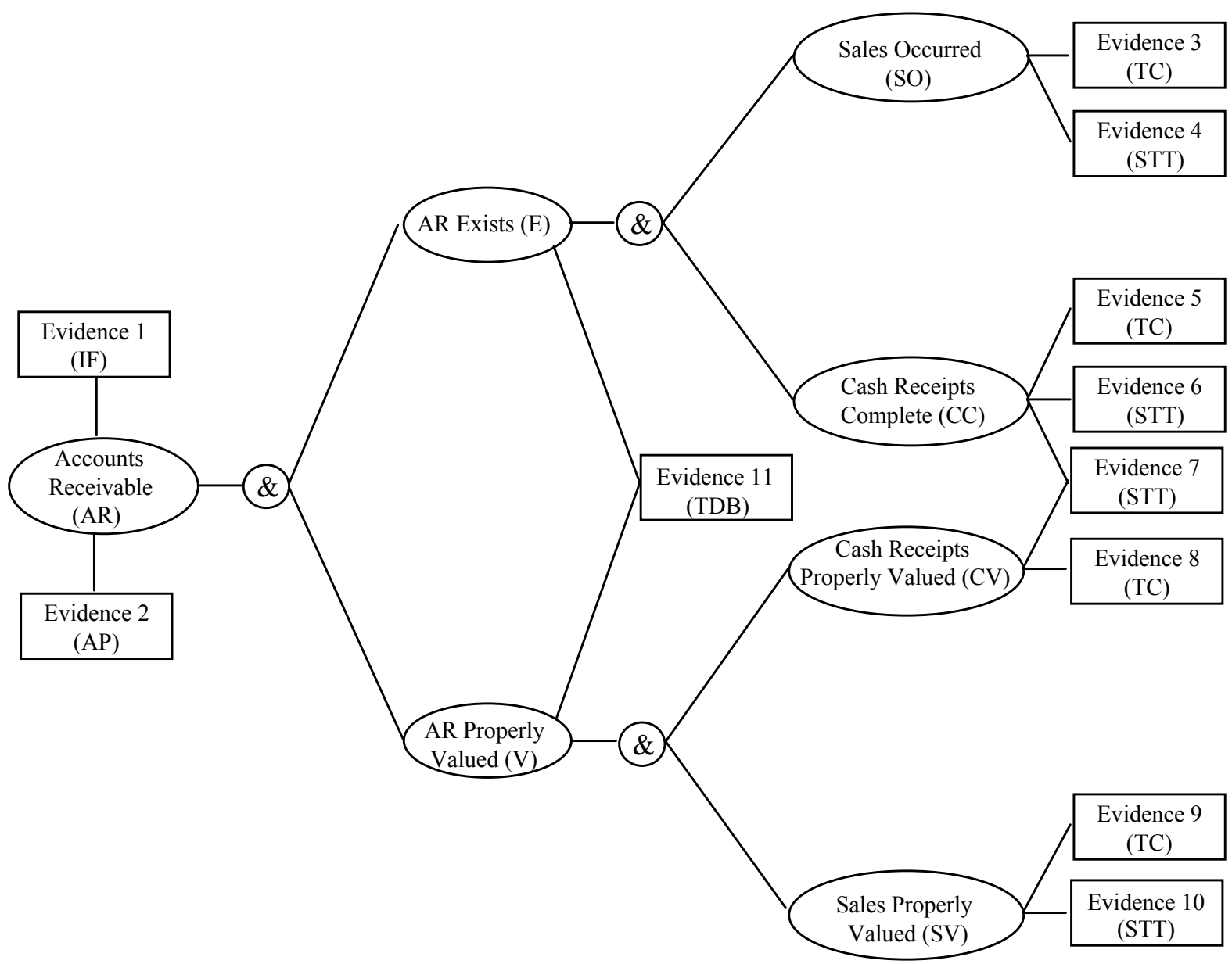

* An ellipse represents a variable and a rectangle represents an item of evidence. A circle with ' $\&$ ' in it represents an 'and' node which implies that the variable on the left of it is met if and only if the variables on its right are met. An item of evidence may consist of one or more than one audit procedure (see Table 1). 


\section{Figure 2}

\section{Markov Tree of the Evidential Network in Figure 1.}
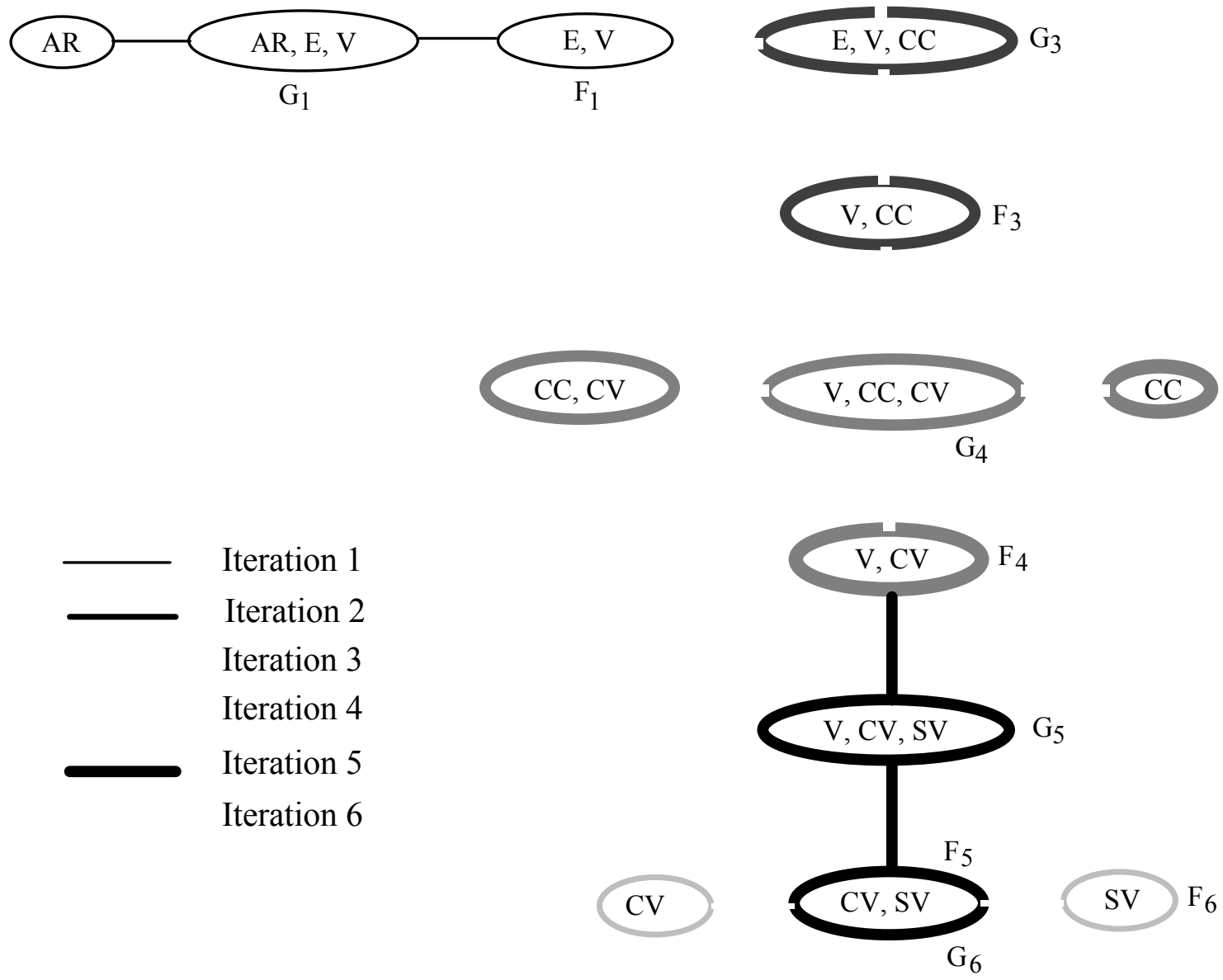


\section{Figure 3}

Markov tree of the evidential network in Figure 1 with the items of evidence attached to the relevant nodes*.

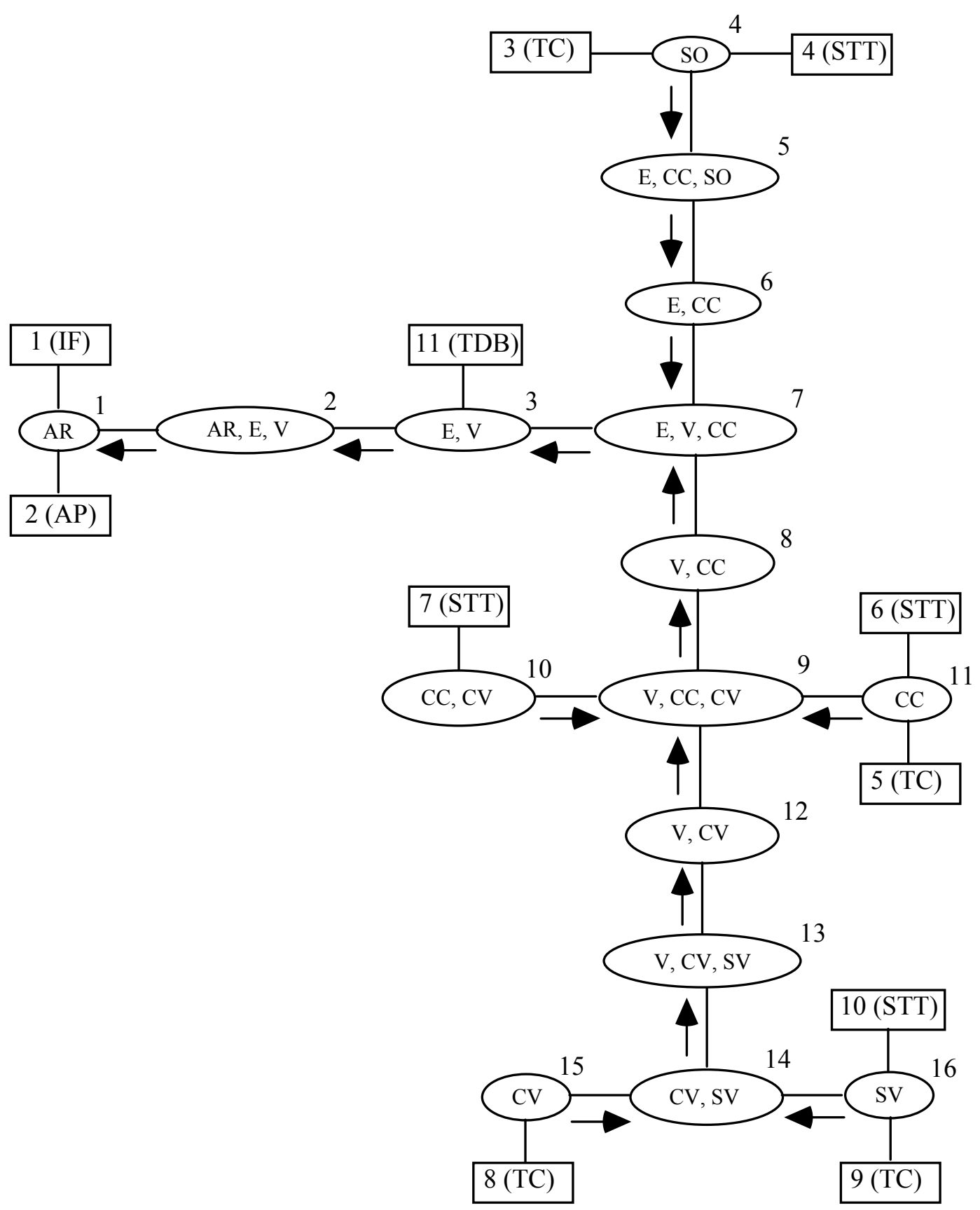

*A rounded box represents a node and a rectangular box represents an item of evidence. All the items of evidence presented here are given in Table 1. The shaded boxes represent 'and' nodes which implies that the left most variable in the node is related to the next two variables through an 'and' relationship. For example, Node 2 is an 'and' node; it implies that the accounts 
receivable balance (AR) is not materially misstated if and only if the existence (E) and valuation (V) objectives have been met. 


\section{Exhibit 1}

Markov tree construction for the evidential network in Figure 1. X represents the set of variables in the evidential network, and $H$ represents the set of subsets of variables over which we have belief functions. The subset of variables in bold faces in $\mathrm{H}_{\mathrm{i}}$ represents the new element $\left(F_{i}\right)$ that has been added to $H_{i-1}$.

\begin{tabular}{|c|c|c|c|}
\hline $\begin{array}{l}X=\{A R \\
H=\{\{A \\
\text { Initializa }\end{array}$ & $\begin{array}{l}\mathrm{V}, \mathrm{CC}, \mathrm{CV}, \mathrm{SO}, \mathrm{SV}\} \\
\{\mathrm{CC}\},\{\mathrm{CV}\},\{\mathrm{SO}\},\{\mathrm{SV}\},\{\mathrm{E} \\
: \mathrm{U}_{0}=\mathrm{X}, \mathrm{H}_{0}=\mathrm{H}, \mathrm{N}=\varnothing, \mathrm{E}=\end{array}$ & \},$\{\mathrm{CC}, \mathrm{C}$ & $\{\mathrm{AR}, \mathrm{E}, \mathrm{V}\},\{\mathrm{E}, \mathrm{CC}, \mathrm{SO}\},\{\mathrm{V}, \mathrm{CV}, \mathrm{SV}\}\}$ \\
\hline $\begin{array}{l}\text { Iteration } \\
\text { number } \\
\text { i }\end{array}$ & $\begin{array}{c}\mathrm{X}_{\mathrm{i}} \text { and } \mathrm{G}_{\mathrm{i}}, \text { where } \\
\mathrm{G}_{\mathrm{i}}=\cup\left\{\mathrm{N} \in \mathrm{H}_{\mathrm{i}-1} \mid \mathrm{X}_{\mathrm{i}} \in \mathrm{N}\right\}\end{array}$ & $\begin{array}{l}\text { No. of } \\
\text { elements } \\
\text { in } G_{i}\end{array}$ & $\begin{array}{l}\mathrm{X}_{\mathrm{i}}, \mathrm{G}_{\mathrm{i}}, \mathrm{F}_{\mathrm{i}}, \mathrm{N}, \mathrm{E}, \mathrm{U}_{\mathrm{i}} \text { and } \mathrm{H}_{\mathrm{i}} \text { with the smallest number of } \\
\text { elements in } \mathrm{G}_{\mathrm{i}} \text { using the algorithm in Appendix A }\end{array}$ \\
\hline 1 & $\begin{array}{ll}\mathrm{AR}: & \{\mathrm{AR}, \mathrm{E}, \mathrm{V}\} \\
\mathrm{E}: & \{\mathrm{AR}, \mathrm{E}, \mathrm{V}, \mathrm{CC}, \mathrm{SO}\} \\
\mathrm{V}: & \{\mathrm{AR}, \mathrm{E}, \mathrm{V}, \mathrm{CV}, \mathrm{SV}\} \\
\mathrm{CC}: & \{\mathrm{E}, \mathrm{CC}, \mathrm{CV}, \mathrm{SO}\} \\
\mathrm{CV}: & \{\mathrm{V}, \mathrm{CC}, \mathrm{CV}, \mathrm{SV}\} \\
\mathrm{SO}: & \{\mathrm{E}, \mathrm{CC}, \mathrm{SO}\} \\
\mathrm{SV}: & \{\mathrm{V}, \mathrm{CV}, \mathrm{SV}\}\end{array}$ & $\begin{array}{l}3 * \\
5 \\
5 \\
4 \\
4 \\
3 \\
3\end{array}$ & $\begin{array}{l}\mathrm{X}_{1}=\mathrm{AR}, \mathrm{G}_{1}=\{\mathrm{AR}, \mathrm{E}, \mathrm{V}\}, \mathrm{F}_{1}=\mathrm{G}_{1}-\mathrm{X}_{1}=\{\mathrm{E}, \mathrm{V}\} \\
\mathrm{N}=\left\{\{\mathrm{AR}\}, \mathrm{G}_{1}, \mathrm{~F}_{1}\right\}, \\
\mathrm{E}=\left\{\left\{\{\mathrm{AR}\}, \mathrm{G}_{1}\right\},\left\{\mathrm{G}_{1}, \mathrm{~F}_{1}\right\}\right\} \\
\mathrm{U}_{1}=\mathrm{U}_{0}-\mathrm{X}_{1}=\{\mathrm{E}, \mathrm{V}, \mathrm{CC}, \mathrm{CV}, \mathrm{SO}, \mathrm{SV}\} \\
\mathrm{H}_{1}=\{\{\mathrm{CC}\},\{\mathrm{CV}\},\{\mathrm{SO}\},\{\mathrm{SV}\},\{\mathrm{E}, \mathrm{V}\},\{\mathrm{CC}, \mathrm{CV}\}, \\
\quad \quad\{\mathrm{E}, \mathrm{CC}, \mathrm{SO}\},\{\mathrm{V}, \mathrm{CV}, \mathrm{SV}\}\} . \\
\text { The above nodes and edges are drawn in Figure } 2 \text { using }\end{array}$ \\
\hline 2 & $\begin{array}{ll}\mathrm{E}: & \{\mathrm{E}, \mathrm{V}, \mathrm{CC}, \mathrm{SO}\} \\
\mathrm{V}: & \{\mathrm{E}, \mathrm{V}, \mathrm{CV}, \mathrm{SV}\} \\
\mathrm{CC}: & \{\mathrm{E}, \mathrm{CC}, \mathrm{CV}, \mathrm{SO}\} \\
\mathrm{CV}: & \{\mathrm{V}, \mathrm{CC}, \mathrm{CV}, \mathrm{SV}\} \\
\mathrm{SO}: & \{\mathrm{E}, \mathrm{CC}, \mathrm{SO}\} \\
\mathrm{SV}: & \{\mathrm{V}, \mathrm{CV}, \mathrm{SV}\}\end{array}$ & $\begin{array}{l}4 \\
4 \\
4 \\
4 \\
3 \\
3\end{array}$ & $\begin{array}{l}\mathrm{X}_{2}=\mathrm{SO}, \mathrm{G}_{2}=\{\mathrm{E}, \mathrm{CC}, \mathrm{SO}\}, \mathrm{F}_{2}=\mathrm{G}_{2}-\mathrm{X}_{2}=\{\mathrm{E}, \mathrm{CC}\} . \\
\text { The new nodes to be added to } \mathrm{N} \text { are: }\{\mathrm{SO}\}, \mathrm{G}_{2}, \mathrm{~F}_{2} . \\
\text { The new edges to be added to } \mathrm{E} \text { are: } \\
\left.\qquad\left\{\{\mathrm{SO}\}, \mathrm{G}_{2}\right\},\left\{\mathrm{G}_{2}, \mathrm{~F}_{2}\right\}\right\} . \\
\mathrm{U}_{2}=\mathrm{U}_{1}-\mathrm{X}_{2}=\{\mathrm{E}, \mathrm{V}, \mathrm{CC}, \mathrm{CV}, \mathrm{SV}\}, \\
\mathrm{H}_{2}=\{\{\mathrm{CC}\},\{\mathrm{CV}\},\{\mathrm{SV}\},\{\mathrm{E}, \mathrm{V}\},\{\mathrm{CC}, \mathrm{CV}\}, \\
\qquad \mathrm{V}, \mathrm{CV}, \mathrm{SV}\},\{\mathrm{E}, \mathrm{CC}\}\} . \\
\text { The above nodes and edges are drawn in Figure } 2 \text { using }\end{array}$ \\
\hline 3 & $\begin{array}{ll}\mathrm{E}: & \{\mathrm{E}, \mathrm{V}, \mathrm{CC}\} \\
\mathrm{V}: & \{\mathrm{E}, \mathrm{V}, \mathrm{CV}, \mathrm{SV}\} \\
\mathrm{CC}: & \{\mathrm{E}, \mathrm{CC}, \mathrm{CV}\} \\
\mathrm{CV} & \{\mathrm{V}, \mathrm{CC}, \mathrm{CV}, \mathrm{SV}\} \\
\mathrm{SV} & \{\mathrm{V}, \mathrm{CV}, \mathrm{SV}\}\end{array}$ & $\begin{array}{l}3 \\
4 \\
3 \\
4 \\
3\end{array}$ & $\begin{array}{l}\mathrm{X}_{3}=\mathrm{E}, \mathrm{G}_{3}=\{\mathrm{E}, \mathrm{V}, \mathrm{CC}\}, \mathrm{F}_{3}=\mathrm{G}_{3}-\mathrm{X}_{3}=\{\mathrm{V}, \mathrm{CC}\} . \\
\text { The new nodes to be added to } \mathrm{N} \text { are: } \mathrm{G}_{3} \text { and } \mathrm{F}_{3} . \\
\text { The new edges to be added to } \mathrm{E} \text { are: } \\
\qquad\left\{\left\{\{\mathrm{E}, \mathrm{CC}\}, \mathrm{G}_{3}\right\},\left\{\{\mathrm{E}, \mathrm{V}\}, \mathrm{G}_{3}\right\},\left\{\mathrm{F}_{3}, \mathrm{G}_{3}\right\}\right\} . \\
\mathrm{U}_{3}=\mathrm{U}_{2}-\mathrm{X}_{3}=\{\mathrm{V}, \mathrm{CC}, \mathrm{CV}, \mathrm{SV}\}, \\
\mathrm{H}_{3}=\{\{\mathrm{CC}\},\{\mathrm{CV}\},\{\mathrm{SV}\},\{\mathrm{CC}, \mathrm{CV}\},\{\mathrm{V}, \mathrm{CV}, \mathrm{SV}\}, \\
\quad \\
\text { TV, CC }\}\} .\end{array}$ \\
\hline
\end{tabular}

* An arrow indicates that the corresponding $\mathrm{G}_{\mathrm{i}}$ has the least number of variables. If there are more than one element with the same (least) number of variables in the corresponding $G_{i}$ then we choose the element that comes first in the alphabetical order (also, see Footnote 5). 


\section{Exhibit 1 (Continued)}

\section{Markov tree construction for the evidential network in Figure 1.}

\begin{tabular}{|c|c|c|c|}
\hline $\begin{array}{l}\mathrm{X}=\{\mathrm{AR} \\
\mathrm{H}=\{\{\mathrm{AR} \\
\text { Initializati }\end{array}$ & $\begin{array}{l}\text { V, CC, CV, SO, SV }\} \\
\{\mathrm{CC}\},\{\mathrm{CV}\},\{\mathrm{SO}\},\{\mathrm{SV}\},\{\mathrm{E}, \\
\mathrm{u}=\mathrm{X}, \mathrm{H}_{0}=\mathrm{H}, \mathrm{N}=\varnothing, \mathrm{E}=\varnothing\end{array}$ & \},$\{\mathrm{CC}, \mathrm{C}$ & $\{\mathrm{AR}, \mathrm{E}, \mathrm{V}\},\{\mathrm{E}, \mathrm{CC}, \mathrm{SO}\},\{\mathrm{V}, \mathrm{CV}, \mathrm{SV}\}\}$ \\
\hline $\begin{array}{l}\text { Iteration } \\
\text { number } \\
\text { i }\end{array}$ & $\begin{array}{c}\mathrm{X}_{\mathrm{i}} \text { and } \mathrm{G}_{\mathrm{i}} \text {, where } \\
\mathrm{G}_{\mathrm{i}}=\cup\left\{\mathrm{N} \in \mathrm{H}_{\mathrm{i}-1} \mid \mathrm{X}_{\mathrm{i}} \in \mathrm{N}\right\}\end{array}$ & $\begin{array}{l}\text { No. of } \\
\text { elements } \\
\text { in } G_{i}\end{array}$ & $\begin{array}{l}\mathrm{X}_{\mathrm{i}}, \mathrm{G}_{\mathrm{i}}, \mathrm{F}_{\mathrm{i}}, \mathrm{N}, \mathrm{E}, \mathrm{U}_{\mathrm{i}} \text { and } \mathrm{H}_{\mathrm{i}} \text { with the smallest number of } \\
\text { elements in } \mathrm{G}_{\mathrm{i}} \text { using the algorithm in Appendix A }\end{array}$ \\
\hline 4 & $\begin{array}{ll}\mathrm{V}: & \{\mathrm{V}, \mathrm{CC}, \mathrm{CV}, \mathrm{SV}\} \\
\mathrm{CC}: & \{\mathrm{V}, \mathrm{CC}, \mathrm{CV}\} \\
\mathrm{CV}: & \{\mathrm{V}, \mathrm{CC}, \mathrm{CV}, \mathrm{SV}\} \\
\mathrm{SV}: & \{\mathrm{V}, \mathrm{CV}, \mathrm{SV}\}\end{array}$ & $\begin{array}{l}4 \\
3 \\
4 \\
3\end{array}$ & $\begin{array}{l}\mathrm{X}_{4}=\mathrm{CC}, \mathrm{G}_{4}=\{\mathrm{V}, \mathrm{CC}, \mathrm{CV}\}, \mathrm{F}_{4}=\mathrm{G}_{4}-\mathrm{X}_{4}=\{\mathrm{V}, \mathrm{CV}\}, \\
\text { The new nodes to be added to } \mathrm{N} \text { are: } \\
\qquad\{\mathrm{CC}\},\{\mathrm{CC}, \mathrm{CV}\}, \mathrm{G}_{4}, \mathrm{~F}_{4} . \\
\text { The new edges to be added to } \mathrm{E} \text { are: } \\
\quad\left\{\left\{\{\mathrm{CC}\}, \mathrm{G}_{4}\right\},\left\{\{\mathrm{CC}, \mathrm{CV}\}, \mathrm{G}_{4}\right\},\left\{\{\mathrm{V}, \mathrm{CC}\}, \mathrm{G}_{4}\right\},\left\{\mathrm{F}_{4}, \mathrm{G}_{4}\right\}\right\} . \\
\mathrm{U}_{4}=\mathrm{U}_{3}-\mathrm{X}_{4}=\{\mathrm{V}, \mathrm{CV}, \mathrm{SV}\}, \\
\mathrm{H}_{4}=\{\{\mathrm{CV}\},\{\mathrm{SV}\},\{\mathrm{V}, \mathrm{CV}, \mathrm{SV}\},\{\mathrm{V}, \mathrm{CV}\}\} . \\
\text { The above nodes and edges are drawn in Figure } 2 \text { using }\end{array}$ \\
\hline $5 \mathrm{~V}:\{\mathrm{V}$ & $\begin{array}{l}\mathrm{V}, \mathrm{SV}\} \\
\mathrm{CV}:\{\mathrm{V}, \mathrm{CV}, \mathrm{SV}\} \\
\mathrm{SV}:\{\mathrm{V}, \mathrm{CV}, \mathrm{SV}\}\end{array}$ & $\begin{array}{l}3 \\
3 \\
3\end{array}$ & $\begin{array}{l}\mathrm{X}_{5}=\mathrm{V}, \mathrm{G}_{5}=\{\mathrm{V}, \mathrm{CV}, \mathrm{SV}\}, \mathrm{F}_{5}=\mathrm{G}_{5}-\mathrm{X}_{5}=\{\mathrm{CV}, \mathrm{SV}\} \\
\text { The new nodes to be added to } \mathrm{N} \text { are } \mathrm{G}_{5} \text { and } \mathrm{F}_{5} . \\
\text { The new edges to be added to } \mathrm{E} \text { are: } \\
\left.\qquad\left\{\{\mathrm{V}, \mathrm{CV}\}, \mathrm{G}_{5}\right\},\left\{\mathrm{F}_{5}, \mathrm{G}_{5}\right\}\right\} \\
\mathrm{U}_{5}=\mathrm{U}_{4}-\mathrm{X}_{5}=\{\mathrm{CV}, \mathrm{SV}\} \\
\mathrm{H}_{5}=\{\{\mathrm{CV}\},\{\mathrm{SV}\},\{\mathrm{CV}, \mathrm{SV}\}\} . \\
\text { The above nodes and edges are drawn in Figure } 2 \text { using }\end{array}$ \\
\hline 6 & $\begin{array}{l}\mathrm{CV}:\{\mathrm{CV}, \mathrm{SV}\} \\
\mathrm{SV}:\{\mathrm{CV}, \mathrm{SV}\}\end{array}$ & $\begin{array}{l}2 \\
2\end{array}$ & $\begin{array}{l}\mathrm{X}_{6}=\mathrm{CV}, \mathrm{G}_{6}=\{\mathrm{CV}, \mathrm{SV}\}, \mathrm{F}_{6}=\mathrm{G}_{6}-\mathrm{X}_{6}=\{\mathrm{SV}\} \\
\text { The new nodes to be added to } \mathrm{N} \text { are }\{\mathrm{CV}\} \text { and } \mathrm{F}_{6} \\
\text { The new edges to be added to } \mathrm{E} \text { are: } \\
\left.\qquad\left\{\{\mathrm{CV}\}, \mathrm{G}_{6}\right\},\left\{\mathrm{F}_{6}, \mathrm{G}_{6}\right\}\right\} . \\
\mathrm{U}_{6}=\mathrm{U}_{5}-\mathrm{X}_{6}=\{\mathrm{SV}\} \\
\mathrm{H}_{6}=\{\mathrm{SV}\} . \\
\text { The above nodes and edges are drawn in Figure } 2 \text { using }\end{array}$ \\
\hline 7 & $\mathrm{SV}:\{\mathrm{SV}\}$ & 1 & $\begin{array}{l}\mathrm{X}_{7}=\mathrm{SV}, \mathrm{G}_{7}=\{\mathrm{SV}\}, \mathrm{F}_{7}=\mathrm{G}_{7}-\mathrm{X}_{7}=\{\varnothing\} . \\
\text { No new nodes to be added to } \mathrm{N} . \\
\text { No new edges to be added to } \mathrm{E} . \\
\mathrm{U}_{7}=\mathrm{U}_{6}-\mathrm{X}_{7}=\{\varnothing\}, \\
\mathrm{H}_{7}=\{\varnothing\} .\end{array}$ \\
\hline
\end{tabular}


Table 1

The Audit Procedures used in Figure 1 (Arens and Loebbecke, 1991: 391-393).

\author{
Evidence \\ Number and \\ Audit Procedure \\ the associated \\ Node No. \\ in Figure 3
}

1 (Node 1) Inherent Factors (IF) - Prior years' experience with the account, related accounting system, and the control environment. Also, the knowledge about the competence and trustworthiness of accounting personnel working in the sales and collection cycle, and other relevant inherent factors.

2 (Node 1) Analytical Procedures (AP) - (i) Review accounts receivable trial balance for large and unusual receivables. (ii) Calculate ratios indicated in carry-forward working papers (not included here) and follow up any significant changes from prior years.

3 (Node 4) Test of Controls (TC) - (i) Account for a sequence of sales invoices in the sales journal. (ii) For selected duplicate invoice numbers from the sales journal, examine underlying documents for indication of internal certification that the total amount recorded in the journal, date, customer name, pricing, extension, and footings have been checked.

4 (Node 4) Substantive Test of Transactions (STT) - (i) Review the sales journal and ledger for unusual transactions and amounts. (ii) Trace recorded sales from the sales journal to the file of supporting documents, which includes a duplicate sales invoice, bill of lading, sales order, and customer order.

5 (Node 11) Test of Controls (TC) - Observe whether a restrictive endorsement is used on cash receipts.

6 (Node 11) Substantive Test of Transactions (STT) - Obtain the prelisting of cash receipts, and trace amounts to the cash receipts journal, testing for name, amount, and date.

7 (Node 10) Substantive Test of Transactions (STT) - Compare the prelisting of cash receipts with the duplicate deposit slip, testing for names, amounts, and dates. Trace the total from the cash receipts journal to the bank statement, testing for dates, amounts of deposit, and delay in deposit.

8 (Node 15) Test of Controls (TC) - Observe whether the accountant reconciles bank account.

9 (Node 16) Test of Controls (TC) - For selected duplicate invoice numbers from the sales journal, examine underlying documents for indication of internal certification that the total amount recorded in the journal, date, customer name, pricing, extension, and footings have been checked.

10 (Node 16) Substantive of Test of Transactions (STT) - Trace selected duplicate invoice numbers from the sales journal to (a) Duplicate sales invoice, and test for the total amount recorded in the journal, date, customer name. Check the pricing, extensions, and footings. (b) Bill of lading, and test for customer name, product description, quantity, and date. (c) Duplicate sales order, and test for customer name, product description, quantity, date, and internal approval. (d) Customer order, and test for customer name, product description, quantity, date, and credit approval by the credit manager.

11 (Node 3) Test of Details of Balance (TDB) - Confirm accounts receivable using positive confirmations above a given amount and perform alternative procedures for all confirmations not returned on the first and second request. 
Srivastava, Rajendra. (1995) The Belief-Function Approach to Aggregating Audit Evidence. International Journal of Intelligent Systems, 10 (3), 329-356. Publisher's Official Version: <http://onlinelibrary.wiley.com/journal/10.1002/\%28ISSN\%291098-111X>. Open Access Version: <http://kuscholarworks.ku.edu/dspace/>. 
Srivastava, Rajendra. (1995) The Belief-Function Approach to Aggregating Audit Evidence. International Journal of Intelligent Systems, 10 (3), 329-356. Publisher's Official Version: <http://onlinelibrary.wiley.com/journal/10.1002/\%28ISSN\%291098-111X>. Open Access Version: <http://kuscholarworks.ku.edu/dspace/>.

\section{Table 2}

Propagation of m-values from Node 4 to Node 6 in the Markov tree in Figure 3.

Only non-zero m-values are given in this table.

\begin{tabular}{|c|c|c|c|c|}
\hline Node & $\begin{array}{l}\text { Frame } \\
\text { of } \\
\text { the node }\end{array}$ & $\begin{array}{l}\text { m-values } \\
\text { defined } \\
\text { at the node }\end{array}$ & $\begin{array}{l}\text { m-values at the node } \\
\text { from the neighboring } \\
\text { node }(\mathrm{s})\end{array}$ & $\begin{array}{l}\text { total } \mathbf{m} \text {-values at the node } \\
\text { ned from combining m-values } \\
\text { is } 3 \text { and } 4 \text { using Dempster's rule) }\end{array}$ \\
\hline 4 & $\Theta_{4}=\{\mathrm{so}, \sim \mathrm{so}\}$ & $\begin{array}{l}\mathbf{m}_{4 \mathrm{TC}}(\mathrm{so})=0.6 \\
\mathbf{m}_{4 \mathrm{TC}}\left(\Theta_{4}\right)=0.4 \\
\mathbf{m}_{4 \mathrm{STT}}(\mathrm{so})=0.7 \\
\mathbf{m}_{4 \mathrm{STT}}\left(\Theta_{4}\right)=0.3\end{array}$ & none & $\begin{array}{l}\mathbf{m}_{4}^{\mathrm{t}}(\mathrm{so})=0.88^{*} \\
\mathbf{m}_{4}^{\mathrm{t}}\left(\Theta_{4}\right)=0.12\end{array}$ \\
\hline 5 & $\begin{aligned} \Theta_{5} \#= & \{(\mathrm{e}, \mathrm{cc}, \mathrm{so}), \\
& (\sim \mathrm{e}, \mathrm{cc}, \sim \mathrm{so}), \\
& (\sim \mathrm{e}, \sim \mathrm{cc}, \mathrm{so}), \\
& (\sim \mathrm{e}, \sim \mathrm{cc}, \sim \mathrm{so})\}\end{aligned}$ & $\mathbf{m}_{5}\left(\Theta_{5}\right)=1.0$ & $\begin{array}{c}\mathbf{m}_{4 \varnothing 5}(\{(\mathrm{e}, \mathrm{cc}, \mathrm{so}),(\sim \mathrm{e}, \sim \mathrm{cc}, \mathrm{so})\}) \\
=\mathbf{m}_{4}^{\mathrm{t}}(\mathrm{so})=0.88 \\
\mathbf{m}_{4 \varnothing 5}\left(\Theta_{5}\right)=\mathbf{m}_{4}^{\mathrm{t}}\left(\Theta_{4}\right)=0.12\end{array}$ & $\begin{array}{l}\mathbf{m}_{5}^{\mathrm{t}}(\{(\mathrm{e}, \mathrm{cc}, \mathrm{so}),(\sim \mathrm{e}, \sim \mathrm{cc}, \mathrm{so})\})=0.88 \\
\mathbf{m}_{5}^{\mathrm{t}}\left(\Theta_{5}\right)=0.12\end{array}$ \\
\hline 6 & $\begin{aligned} \Theta_{6}= & \{(\mathrm{e}, \mathrm{cc}),(\mathrm{e}, \sim \mathrm{cc}) \\
& (\sim \mathrm{e}, \mathrm{cc}),(\sim \mathrm{e}, \sim \mathrm{cc})\}\end{aligned}$ & $\mathbf{m}_{6}\left(\Theta_{6}\right)=1.0$ & $\begin{array}{l}\mathbf{m}_{5 \varnothing 6}(\{(\mathrm{e}, \mathrm{cc}),(\sim \mathrm{e}, \sim \mathrm{cc})\}) \\
=\mathbf{m}_{5}^{\mathrm{t}}(\{(\mathrm{e}, \mathrm{cc}, \mathrm{so}),(\sim \mathrm{e}, \sim \mathrm{cc}, \mathrm{so})\})=0.88 \\
\mathbf{m}_{5 \varnothing 6}\left(\Theta_{6}\right)=\mathbf{m}_{5}^{\mathrm{t}}\left(\Theta_{5}\right)=0.12\end{array}$ & $\begin{array}{l}\mathbf{m}_{6}^{\mathrm{t}}(\{(\mathrm{e}, \mathrm{cc}),(\sim \mathrm{e}, \sim \mathrm{cc})\})=0.88 \\
\mathbf{m}_{6}^{\mathrm{t}}\left(\Theta_{6}\right)=0.12\end{array}$ \\
\hline
\end{tabular}

\footnotetext{
* Since there is no conflict between the two items of evidence, the renormalization constant in Dempster's rule (Footnote 9) is 1 and the combined $\mathbf{m}$-values are: $\mathbf{m}_{4}^{\mathrm{t}}(\mathrm{so})=\mathbf{m}_{4 \mathrm{TC}}(\mathrm{so}) \mathbf{m}_{4 \mathrm{STT}}(\mathrm{so})+\mathbf{m}_{4 \mathrm{TC}}(\mathrm{so}) \mathbf{m}_{4 \mathrm{STT}}\left(\Theta_{4}\right)+\mathbf{m}_{4 \mathrm{TC}}\left(\Theta_{4}\right) \mathbf{m}_{4 \mathrm{STT}}(\mathrm{so})=0.6 \mathrm{x} 0.7+0.6 \mathrm{x} 0.3+0.4 \mathrm{x} 0.7=0.88, \mathbf{m}_{4}^{\mathrm{t}}(\sim \mathrm{so})=\mathbf{m}_{4 \mathrm{TC}}(\sim \mathrm{so}) \mathbf{m}_{4 \mathrm{STT}}(\sim \mathrm{so})+$ $\mathbf{m}_{4 \mathrm{TC}}(\sim \mathrm{so}) \mathbf{m}_{4 \mathrm{STT}}\left(\Theta_{4}\right)+\mathbf{m}_{4 \mathrm{TC}}\left(\Theta_{4}\right) \mathbf{m}_{4 \mathrm{STT}}(\sim \mathrm{so})=0$, and $\mathbf{m}_{4} \mathrm{t}_{4}\left(\Theta_{4}\right)=\mathbf{m}_{4 \mathrm{TC}}\left(\Theta_{4}\right) \mathbf{m}_{4 \mathrm{STT}}\left(\Theta_{4}\right)=0.4 \mathrm{x} 0.3=0.12$.

\# In general, the frame of Node 5 contains the following eight elements: $\{(\mathrm{e}, \mathrm{cc}, \mathrm{so}),(\mathrm{e}, \mathrm{cc}, \sim \mathrm{so}),(\mathrm{e}, \sim \mathrm{cc}, \mathrm{so}),(\mathrm{e}, \sim \mathrm{cc}, \sim \mathrm{so}),(\sim \mathrm{e}, \mathrm{cc}, \mathrm{so}),(\sim \mathrm{e}, \mathrm{cc}, \sim \mathrm{so}),(\sim \mathrm{e}, \sim \mathrm{cc}, \mathrm{so})$, $(\sim \mathrm{e}, \sim \mathrm{cc}, \sim \mathrm{so})\}$. Since this node is an 'and' node, that is, e is true if and only if cc and so were true, the corresponding non-zero $\mathbf{m}-\mathrm{value}$ is $\mathbf{m}(\{(\mathrm{e}, \mathrm{cc}, \mathrm{so})$, $(\sim \mathrm{e}, \mathrm{cc}, \sim \mathrm{so}),(\sim \mathrm{e}, \sim \mathrm{cc}, \mathrm{so}),(\sim \mathrm{e}, \sim \mathrm{cc}, \sim \mathrm{so})\})=1.0$. The effect of this $\mathbf{m}$-value is that the frame of Node 5 is effectively reduced to a four-element set: $\{(\mathrm{e}, \mathrm{cc}$, so $)$, ( e , cc, $\sim$ so $),(\sim \mathrm{e}, \sim \mathrm{cc}, \mathrm{so}),(\sim \mathrm{e}, \sim \mathrm{cc}, \sim \mathrm{so})\}$ with a vacuous belief function over this set.
} 
Srivastava, Rajendra. (1995) The Belief-Function Approach to Aggregating Audit Evidence. International Journal of Intelligent Systems, 10 (3), 329-356. Publisher's Official Version: <http://onlinelibrary.wiley.com/journal/10.1002/\%28ISSN\%291098-111X>. Open Access Version: <http://kuscholarworks.ku.edu/dspace/>.

\section{Table 3}

Propagation of m-values from Nodes 15 and 16 to Node 12 in the Markov tree in Figure 3.

Only non-zero $\mathrm{m}$-values are given in this table.

\begin{tabular}{|c|c|c|c|c|}
\hline Node & $\begin{array}{l}\text { Frame } \\
\text { of } \\
\text { the node }\end{array}$ & $\begin{array}{l}\text { m-values } \\
\text { defined } \\
\text { at the node }\end{array}$ & $\begin{array}{l}\text { m-values at the node } \\
\text { from the neighboring } \\
\qquad \operatorname{node}(\mathrm{s})\end{array}$ & $\begin{array}{c}\text { Total m-values at the node } \\
\text { (Obtained from combining m-values } \\
\text { in columns } 3 \text { and } 4 \text { using Dempster's rule) }\end{array}$ \\
\hline 16 & $\Theta_{16}=\{\mathrm{sv}, \sim \mathrm{sv}\}$ & $\begin{array}{l}\mathbf{m}_{16 \mathrm{TC}}(\mathrm{sv})=0.6 \\
\mathbf{m}_{16 \mathrm{TC}}\left(\Theta_{16}\right)=0.4 \\
\mathbf{m}_{16 \mathrm{STT}}(\mathrm{sv})=0.7 \\
\mathbf{m}_{16 \mathrm{STT}}\left(\Theta_{16}\right)=0.3\end{array}$ & none & $\begin{aligned} \mathbf{m}_{16}^{\mathrm{t}}{ }_{16}(\mathrm{sv})= & \mathbf{m}_{16 \mathrm{TC}}(\mathrm{sv}) \mathbf{m}_{16 \mathrm{STT}}(\mathrm{sv}) \\
& +\mathbf{m}_{16 \mathrm{TC}}(\mathrm{sv}) \mathbf{m}_{16 \mathrm{STT}}\left(\Theta_{16}\right) \\
& +\mathbf{m}_{16 \mathrm{TC}}\left(\Theta_{16}\right) \mathbf{m}_{16 \mathrm{STT}}(\mathrm{sv})=0.88 \\
\mathbf{m}_{16} \mathrm{t}_{16}\left(\Theta_{16}\right) & =\mathbf{m}_{16 \mathrm{TC}}\left(\Theta_{16}\right) \mathbf{m}_{16 \mathrm{STT}}\left(\Theta_{16}\right)=0.12\end{aligned}$ \\
\hline 15 & $\Theta_{15}=\{\mathrm{cv}, \sim \mathrm{cv}\}$ & $\begin{array}{l}\mathbf{m}_{15 \mathrm{TC}}(\mathrm{cv})=0.6 \\
\mathbf{m}_{15 \mathrm{TC}}\left(\Theta_{15}\right)=0.4\end{array}$ & none & $\begin{array}{l}\mathbf{m}_{15}^{\mathrm{t}}(\mathrm{cv})=0.6 \\
\mathbf{m}_{15}^{\mathrm{t}}\left(\Theta_{15}\right)=0.4\end{array}$ \\
\hline 14 & $\begin{aligned} \Theta_{14}= & \{(\mathrm{cv}, \mathrm{sv}) \\
& (\mathrm{cv}, \sim \mathrm{sv}) \\
& (\sim \mathrm{cv}, \mathrm{sv}) \\
& (\sim \mathrm{cv}, \sim \mathrm{sv})\}\end{aligned}$ & $\mathbf{m}_{14}\left(\Theta_{14}\right)=1.0$ & $\begin{array}{l}\mathbf{m}_{16 \varnothing 14}(\{(\mathrm{cv}, \mathrm{sv}),(\sim \mathrm{cv}, \mathrm{sv})\})=\mathbf{m}_{16}^{\mathrm{t}}(\mathrm{sv})=0.88 \\
\mathbf{m}_{16 \varnothing 14}\left(\Theta_{14}\right)=\mathbf{m}_{16}^{\mathrm{t}}{ }_{16}\left(\Theta_{16}\right)=0.12 \\
\mathbf{m}_{15 \varnothing 14}(\{(\mathrm{cv}, \mathrm{sv}),(\mathrm{cv}, \sim \mathrm{sv})\})=\mathbf{m}_{15}^{\mathrm{t}}(\mathrm{cv})=0.6 \\
\mathbf{m}_{15 \varnothing 14}\left(\Theta_{14}\right)=\mathbf{m}_{15}{ }_{15}\left(\Theta_{15}\right)=0.4\end{array}$ & $\begin{array}{l}\mathbf{m}_{14}^{\mathrm{t}}(\mathrm{cv}, \mathrm{sv})=0.528^{\#} \\
\mathbf{m}_{14}^{\mathrm{t}}(\{(\mathrm{cv}, \mathrm{sv}),(\sim \mathrm{cv}, \mathrm{sv})\})=0.352 \\
\mathbf{m}_{14}^{\mathrm{t}}(\{(\mathrm{cv}, \mathrm{sv}),(\mathrm{cv}, \sim \mathrm{sv})\})=0.072 \\
\mathbf{m}_{14}^{\mathrm{t}}\left(\Theta_{14}\right)=0.048\end{array}$ \\
\hline 13 & $\begin{array}{c}\Theta_{13}^{*}=\{(\mathrm{v}, \mathrm{cv}, \mathrm{sv}) \\
\quad(\sim \mathrm{v}, \mathrm{cv}, \sim \mathrm{sv}) \\
(\sim \mathrm{V}, \sim \mathrm{cv}, \mathrm{sv}) \\
\quad(\sim \mathrm{v}, \sim \mathrm{cV}, \sim \mathrm{sv})\}\end{array}$ & $\mathbf{m}_{13}\left(\Theta_{13}\right)=1.0$ & $\begin{array}{l}\mathbf{m}_{14 \varnothing 13}(\mathrm{v}, \mathrm{cv}, \mathrm{sv})=\mathbf{m}_{14}^{\mathrm{t}}(\mathrm{cv}, \mathrm{sv})=0.528 \\
\mathbf{m}_{14} \varnothing{ }_{13}(\{(\mathrm{v}, \mathrm{cv}, \mathrm{sv}),(\sim \mathrm{v}, \sim \mathrm{cv}, \mathrm{sv})\}) \\
\quad=\mathbf{m}_{14}^{\mathrm{t}}(\{(\mathrm{cv}, \mathrm{sv}),(\sim \mathrm{cv}, \mathrm{sv})\})=0.352 \\
\mathbf{m}_{14} \varnothing{ }_{13}(\{(\mathrm{v}, \mathrm{cv}, \mathrm{sv}),(\sim \mathrm{v}, \mathrm{cv}, \sim \mathrm{sv})\}) \\
\quad=\mathbf{m}_{14}^{\mathrm{t}}(\{(\mathrm{cv}, \mathrm{sv}),(\mathrm{cv}, \sim \mathrm{sv})\})=0.072 \\
\mathbf{m}_{14 \varnothing 13}\left(\Theta_{13}\right)=\mathbf{m}_{14}^{\mathrm{t}}\left(\Theta_{14}\right)=0.048\end{array}$ & $\begin{array}{l}\mathbf{m}_{13}^{\mathrm{t}}(\mathrm{v}, \mathrm{cv}, \mathrm{sv})=0.528 \\
\mathbf{m}_{13}^{\mathrm{t}}(\{(\mathrm{v}, \mathrm{cv}, \mathrm{sv}),(\sim \mathrm{v}, \sim \mathrm{cv}, \mathrm{sv})\})=0.352 \\
\mathbf{m}_{13}^{\mathrm{t}}(\{(\mathrm{v}, \mathrm{cv}, \mathrm{sv}),(\sim \mathrm{v}, \mathrm{cv}, \sim \mathrm{sv})\})=0.072 \\
\mathbf{m}_{13}^{\mathrm{t}}\left(\Theta_{13}\right)=0.048\end{array}$ \\
\hline 12 & $\begin{aligned} \Theta_{12}= & \{(\mathrm{v}, \mathrm{cv}) \\
& (\mathrm{v}, \sim \mathrm{cv}) \\
& (\sim \mathrm{v}, \mathrm{cv}), \\
& (\sim \mathrm{v}, \sim \mathrm{cv})\}\end{aligned}$ & $\mathbf{m}_{12}\left(\Theta_{12}\right)=1.0$ & $\begin{array}{l}\mathbf{m}_{13 \varnothing 12}(\mathrm{v}, \mathrm{cv})=\mathbf{m}_{13}^{\mathrm{t}}(\mathrm{v}, \mathrm{cv}, \mathrm{sv})=0.528 \\
\mathbf{m}_{13 \varnothing 12}(\{(\mathrm{v}, \mathrm{cv}),(\sim \mathrm{v}, \sim \mathrm{cv})\}) \\
\quad=\mathbf{m}_{13}^{\mathrm{t}}(\{(\mathrm{v}, \mathrm{cv}, \mathrm{sv}),(\sim \mathrm{v}, \sim \mathrm{cv}, \mathrm{sv})\})=0.352 \\
\mathbf{m}_{13 \varnothing 12}(\{(\mathrm{v}, \mathrm{cv}),(\sim \mathrm{v}, \mathrm{cv})\}) \\
\quad=\mathbf{m}_{13}^{\mathrm{t}}(\{(\mathrm{v}, \mathrm{cv}, \mathrm{sv}),(\sim \mathrm{v}, \mathrm{cv}, \sim \mathrm{sv})\})=0.072 \\
\mathbf{m}_{13 \varnothing 12}\left(\Theta_{12}\right)=\mathbf{m}_{13}^{\mathrm{t}}\left(\Theta_{13}\right)=0.048\end{array}$ & $\begin{array}{l}\mathbf{m}_{12}^{\mathrm{t}}(\mathrm{v}, \mathrm{cv})=0.528 \\
\mathbf{m}_{12}^{\mathrm{t}}(\{(\mathrm{v}, \mathrm{cv}),(\sim \mathrm{v}, \sim \mathrm{cv})\})=0.352 \\
\mathbf{m}_{12}^{\mathrm{t}}(\{(\mathrm{v}, \mathrm{cv}),(\sim \mathrm{v}, \mathrm{cv})\})=0.072 \\
\mathbf{m}_{12}^{\mathrm{t}}\left(\Theta_{12}\right)=0.048\end{array}$ \\
\hline
\end{tabular}

\# See Footnote 11 for computations.

* Node 13 is an 'and' node by assumption, it implies that $\mathrm{v}$ is true if and only if cv and sv are true. Also, see the second footnote in Table 2. 
Srivastava, Rajendra. (1995) The Belief-Function Approach to Aggregating Audit Evidence. International Journal of Intelligent Systems, 10 (3), 329-356. Publisher's Official Version: <http://onlinelibrary.wiley.com/journal/10.1002/\%28ISSN\%291098-111X> Open Access Version: <http://kuscholarworks.ku.edu/dspace/>. 
Srivastava, Rajendra. (1995) The Belief-Function Approach to Aggregating Audit Evidence. International Journal of Intelligent

Systems, 10 (3), 329-356. Publisher's Official Version: <http://onlinelibrary.wiley.com/journal/10.1002/\%28ISSN\%291098-111X>.

Open Access Version: <http://kuscholarworks.ku.edu/dspace/>.

\section{Table 4}

Propagation of m-values from Nodes 10, 11 and 12 to Node 9 in the Markov tree in Figure 3.

Only non-zero $\mathbf{m}$-values are given in this table. Values of $\mathbf{m}^{\mathrm{t}}{ }_{12}$ are given in Table 3

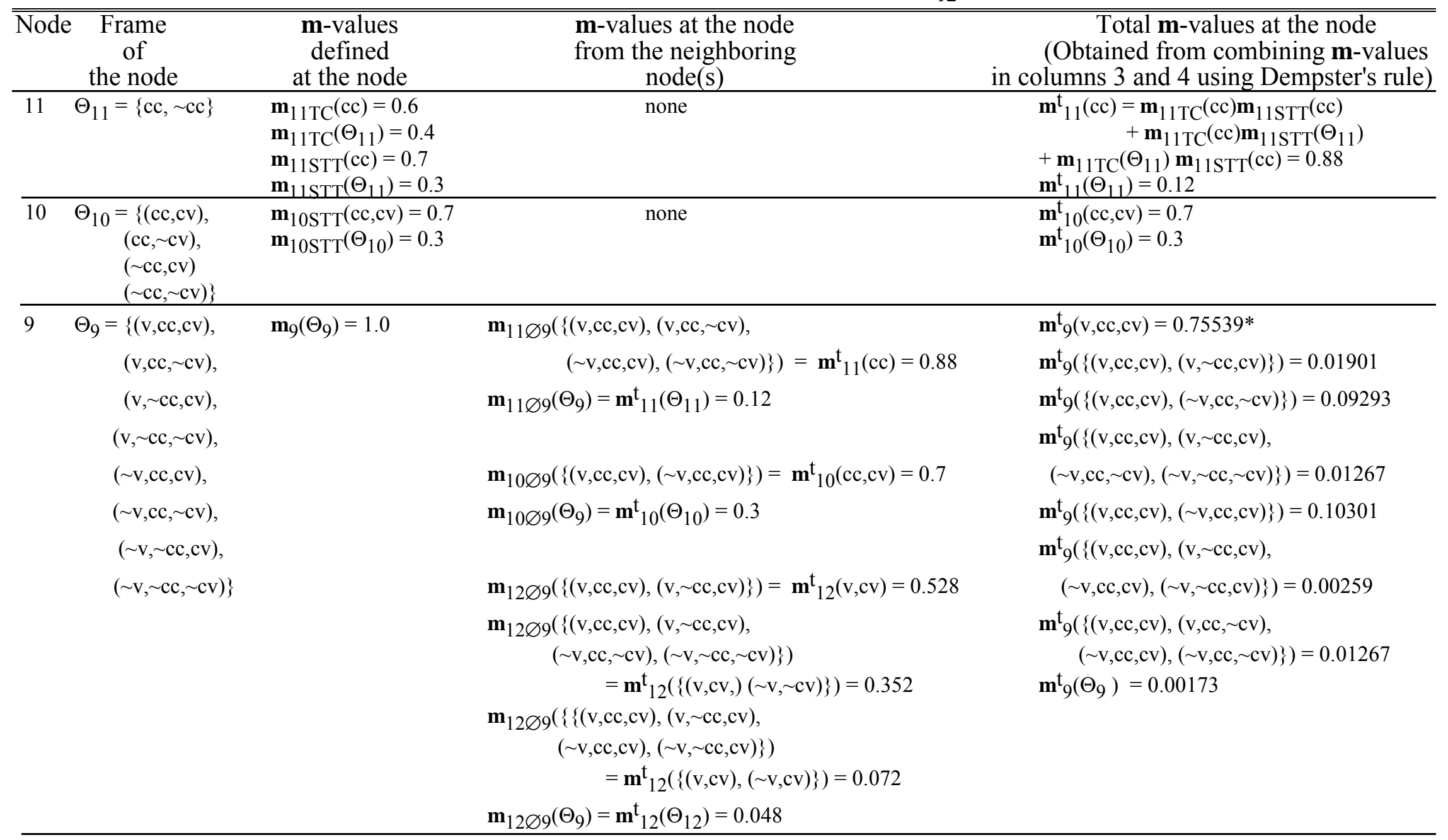

* See Footnote 12 for details. 
Srivastava, Rajendra. (1995) The Belief-Function Approach to Aggregating Audit Evidence International Journal of Intelligent Systems, 10 (3), 329-356. Publisher's Official Version: <http://onlinelibrary.wiley.com/journal/10.1002/\%28ISSN\%291098-111X>. Open Access Version: <http://kuscholarworks.ku.edu/dspace/>.

\section{Table 5}

Propagation of m-values from Nodes 6 and 8 to Node 7 in the Markov tree in Figure 3. Only non-zero m-values are given in this table. Values of $\mathrm{m}_{6}^{\mathrm{t}}$ and $\mathrm{m}_{9}^{\mathrm{t}}$ are given in Tables 2 and 4, respectively.

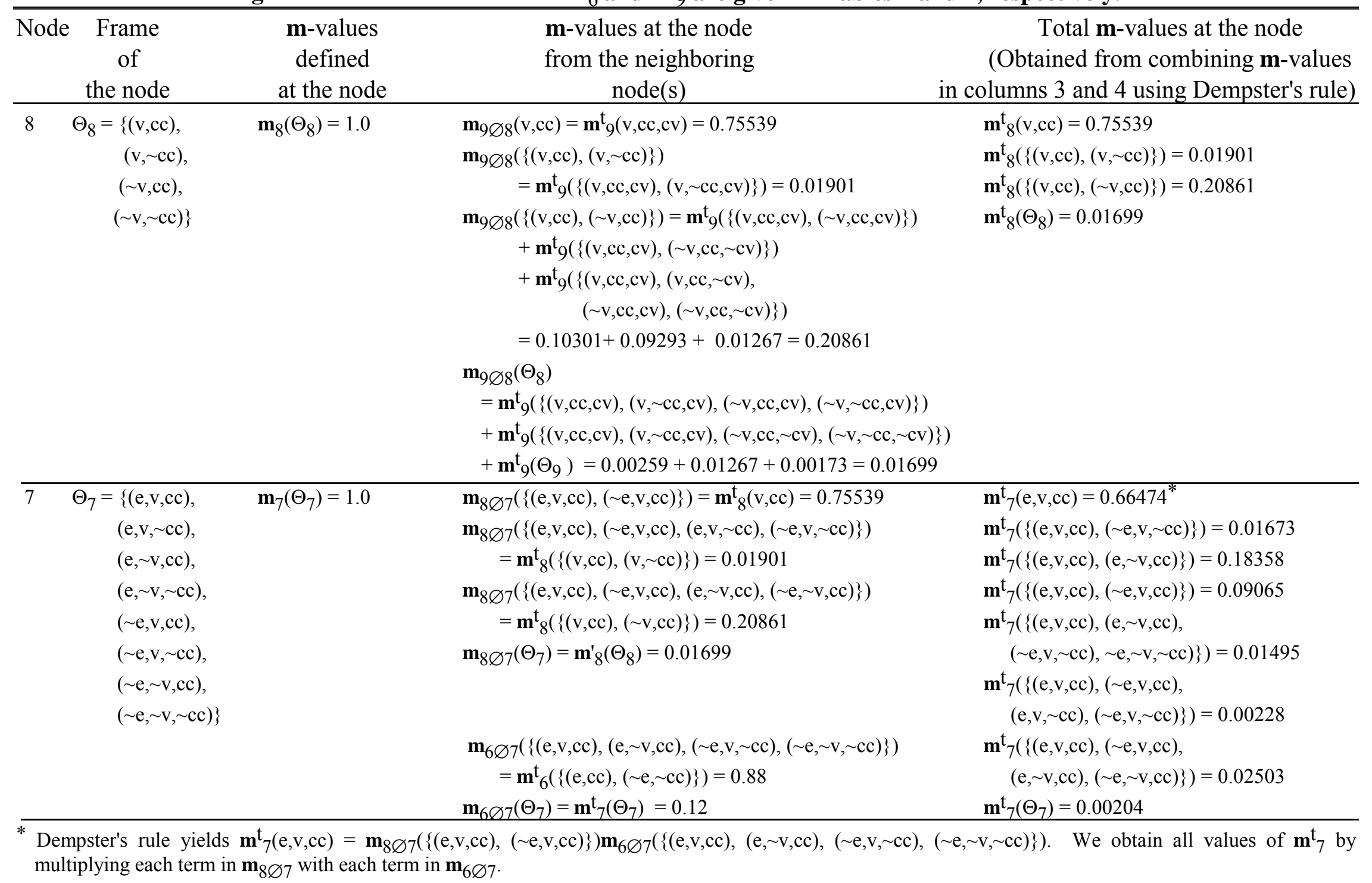


Srivastava, Rajendra. (1995) The Belief-Function Approach to Aggregating Audit Evidence. International Journal of Intelligent Systems, 10 (3), 329-356. Publisher's Official Version: <http://onlinelibrary.wiley.com/journal/10.1002/\%28ISSN\%291098-111X>. Open Access Version: <http://kuscholarworks.ku.edu/dspace/>.

\section{Table 6}

Propagation of m-values from Node 7 to Node 1 in the Markov tree in Figure 3.

Only non-zero $\mathrm{m}$-values are given in this table. Values of $\mathrm{m}_{7}^{\mathrm{t}}$ are given in Table 5.

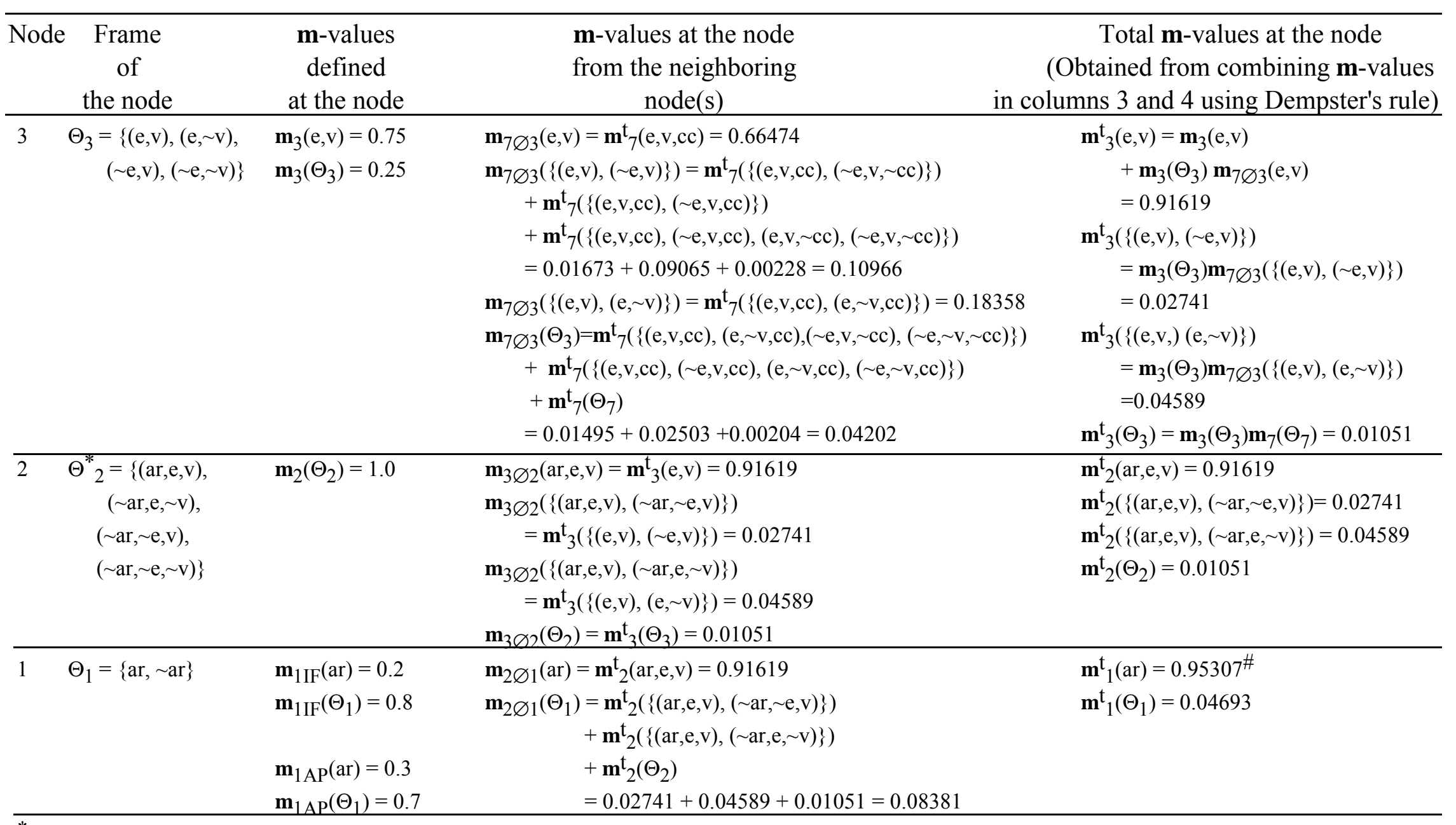

* Node 2 is an 'and' node by assumption, this implies that ar is true if and only if e and $\mathrm{v}$ are true. Also, see the second footnote in Table 2.

\# Since $\left.\mathbf{m}_{1}^{\mathrm{t}}\left(\Theta_{1}\right)=\mathbf{m}_{1 \mathrm{IF}}\left(\Theta_{1}\right) \mathbf{m}_{1 \mathrm{AP}}\left(\Theta_{1}\right) \mathbf{m}_{2 \varnothing 1} \Theta_{1}\right)=0.04693$, and $\mathbf{m}_{1}^{\mathrm{t}}(\sim \operatorname{ar})=0$, we have $\mathbf{m}_{1}^{\mathrm{t}}(\operatorname{ar})=1-\mathbf{m}_{1}^{\mathrm{t}}(\sim \operatorname{ar})-\mathbf{m}_{1}^{\mathrm{t}}\left(\Theta_{1}\right)=0.95307$. 


\section{APPENDIX A}

\section{Markov Tree}

A Markov tree is a topological tree, whose nodes are subsets of variables, with the property that if a variable belongs to two distinct nodes, then every node lying on the path between these two nodes contains the variable (Shenoy 1991). The properties of Markov trees and how to construct such trees have been studied and discussed by Kong (1986) and Mellouli (1987). Also, Markov trees are discussed in the computer science literature under the name "join trees" (e.g., see Maier 1983). The purpose of this appendix is to summarize the algorithm for constructing a Markov tree from an evidential network.

In order to describe the algorithm, we need to present a formal definition of a Markov tree. A Markov tree is characterized by a set of nodes $\mathrm{N}$ and a set of edges $\mathrm{E}$ where each edge is a twoelement subset of $\mathrm{N}$ such that:

(i) $(\mathrm{N}, \mathrm{E})$ is a tree.

(ii) If $N_{\text {and }} \mathrm{N}^{\prime}$ are two distinct nodes in $\mathrm{N}$, and $\left\{\mathrm{N}, \mathrm{N}^{\prime}\right\}$ is an edge, i.e., $\left\{\mathrm{N}, \mathrm{N}^{\prime}\right\} \in \mathrm{E}^{\prime}$, then $\mathrm{N} \cap \mathrm{N}^{\prime} \neq \varnothing$.

(ii) If $\mathrm{N}$ and $\mathrm{N}^{\prime}$ are distinct nodes of $\mathrm{N}$, and $\mathrm{X}$ is a variable in both $\mathrm{N}$ and $\mathrm{N}^{\prime}$, then $\mathrm{X}$ is in every node on the path from $\mathrm{N}$ to $\mathrm{N}$ '.

In order to construct a Markov tree from an evidential network, we first need to determine the set $\mathrm{H}$ of subset of variables that have belief functions associated. As discussed in Section I, understanding how various items of evidence bear on different variables of interest and knowing the logical relationships between different variables provide the set $\mathrm{H}$. We will use Kong's algorithm (1986) as discussed below to construct a Markov tree from $\mathrm{H}$.

Let us define $X$ to be the set of variables in H. Shenoy (1991) describes the Markov tree construction process in terms of pseudo-Pascal as: 
